\title{
O gênero Oxalis L. (Oxalidaceae) no Rio Grande do Sul, Brasil
}

\author{
The genus Oxalis L. (Oxalidaceae) in Rio Grande do Sul, Brazil
}

\author{
Daniele Grigoletto ${ }^{1}$, Tatiane Bertuzzi², Sônia Maria Eisinger ${ }^{3}$, \\ Thaís Scotti do Canto-Dorow ${ }^{* 4}$, Cícero Schneider Colusso ${ }^{5}$ \\ ${ }^{1,2}$ MSc. em Agrobiologia, Universidade Federal de Santa Maria, Santa Maria, Brasil. \\ 3,4Professora do Centro de Ciências Naturais e Exatas, Departamento de Biologia, Universidade Federal de Santa \\ Maria, Santa Maria, Brasil. \\ ${ }^{5}$ Graduando Ciências Biológicas, Universidade Federal de Santa Maria, Santa Maria, Brasil.
}

\begin{abstract}
Resumo
O objetivo deste trabalho foi o de realizar o levantamento do gênero Oxalis no estado do Rio Grande do Sul, fornecendo meios para a identificação de suas espécies. O estudo foi realizado com base em revisão de literatura especializada e de sites específicos da área de taxonomia; revisão de herbários; e coleta de material a campo, abrangendo o estado. No Rio Grande do Sul, o gênero Oxalis está representado por 27 espécies. Destas, duas representam novas ocorrências, Oxalis subvillosa no Rio Grande do Sul, e Oxalis lindneri, no Brasil. São fornecidos chave analítica, descrições morfológicas, ilustrações e dados sobre hábitat, distribuição, período de floração e frutificação.
\end{abstract}

Palavras-chave: Taxonomia, biodiversidade, preservação.

\begin{abstract}
This work aims at caring out the survey of the genus Oxalis in the state of Rio Grande do Sul, offering means for the species identification. The study was carried out based on review of specialized literature and specific websites in the field of taxonomy; revision of the Herbarium; and field work throughout the state. In Rio Grande do Sul, the genus Oxalis is represented by 27 species. One of these species is a new occurrence in Rio Grande do Sul State, Oxalis subvillosa. Other of them, Oxalis lindneri, is a new record in Brazil. Analytical key, morphological descriptions, illustrations and data concerning the habitat, distribution, flowering and fruiting period are supplied.
\end{abstract}

Keywords: Taxonomy, biodiversity, preservation. 


\section{Introdução}

$\mathrm{O}$ xalidaceae R. Br. compreende cinco gêneros e cerca de 770 espécies (Stevens, 2001), distribuídas nas regiões tropicais e subtropicais (Souza \& Lorenzi, 2008). De acordo com Abreu e Fiaschi (2013), a família está representada no Brasil por 118 espécies, 19 subespécies e 17 variedades, distribuídas nos gêneros Averrhoa L., Biophytum DC. e Oxalis L., sendo este o mais numeroso. Averrhoa ocorre de forma subespontânea, enquanto, Biophytum e Oxalis são nativos (Souza \& Lorenzi, 2008).

Os representantes de Oxalis são encontrados em ambientes diversificados, destacando-se as áreas abertas como campos, florestas e áreas antropizadas (Fiaschi \& Conceição, 2005). Em relação à importância econômica, são considerados ornamentais, infestantes (Kissmann \& Groth, 2000), podendo ser utilizados na alimentação e na medicina (Corrêa, 1926; 1984).

No Brasil, não há uma pesquisa detalhada abordando a taxonomia de Oxalis, contudo, destacam-se os estudos regionais como os realizados na Floresta Atlântica para onde são citadas 63 espécies de Oxalis (Abreu \& Fiaschi, 2009), no estado de Pernambuco, nove espécies (Abreu, 2007), no Parque Estadual das Fontes de Ipiranga no estado de São Paulo, quatro espécies (Souza \& Bianchini, 2000), no estado de São Paulo, 23 espécies (Fiaschi \& Conceição, 2005), e no estado de Santa Catarina, 42 espécies, das quais 16 não encontradas, mas citadas pela autora por considerar possível a ocorrência (Lourteig, 1983).

Não existem trabalhos específicos para o Rio Grande do Sul, somente listas de ocorrência, como o trabalho de Abreu e Fiaschi (2013) que menciona 26 espécies e duas subespécies, das quais Oxalis brasiliensis G.Lodd., Oxalis lasiopetala Zucc., Oxalis paludosa A.St.-Hil., Oxalis perdicaria (Molina) Bertero, Oxalis refracta A.St.-Hil. e Oxalis sellowiana Zucc. são exclusivas do Rio Grande do Sul.

Este trabalho visa conhecer e registrar a diversidade do gênero Oxalis no Rio Grande do Sul, fornecendo meios para a identificação de suas espécies como chave analítica, descrições morfológicas, ilustrações, dados sobre hábitat, distribuição, período de floração e de frutificação.

\section{Material e métodos}

O estudo baseou-se em levantamento bibliográfico, consulta de sites específicos da área da taxonomia, revisão de herbários, coletas e observações a campo, além de estudo morfológico.

Foram examinados materiais dos herbários que seguem representados pelas siglas de acordo com Thiers (2012): ICN, PACA, PEL, SMDB, SI. Ainda, foi revisado material do herbário HUCS (Universidade de Caxias do Sul), cuja sigla não está oficializada. Para este artigo, foi realizada uma seleção do material revisado, citando-se, no máximo, uma coleta por município.
Realizaram-se coletas de material em todas as regiões fisiográficas do Rio Grande do Sul conforme Fortes (1959), durante as quatro estações do ano, no período de março de 2011 a março de 2012. As expedições foram definidas com base na revisão da literatura e nas informações contidas nas exsicatas dos herbários revisados. Os exemplares coletados foram fotografados no seu ambiente e herborizados para posterior identificação e inclusão no Herbário SMDB pertencente ao Departamento de Biologia da Universidade Federal de Santa Maria.

Foram selecionados 10 indivíduos de cada espécie, oriundos de coletas ou de herbários, abrangendo a maior variação morfológica, para caracterização quantitativa e qualitativa. Esses dados foram utilizados na construção da chave analítica e das descrições. A terminologia geral da morfologia seguiu Appezzato-da-Glória (2003), Gonçalves e Lorenzi (2011) e, para a forma dos frutos, utilizou-se Radford et al. (1974).

Os dados sobre o hábitat, período de floração, período de frutificação e distribuição no Rio Grande do Sul foram retirados das etiquetas de exsicatas depositadas nos herbários revisados e nas observações realizadas a campo.

As ilustrações do hábito foram feitas a partir de cópias reprográficas de exemplares herborizados e posterior cobertura com nanquim em papel vegetal. Os detalhes da morfologia foram ilustrados com auxílio de câmara clara acoplada a microscópio estereoscópio, a partir de exemplares herborizados e posterior desenho a nanquim em papel vegetal.

\section{Resultados e discussão}

Descrição do gênero Oxalis L.

Ervas a subarbustos. Caule subterrâneo do tipo cormo, bulbo escamoso ou caule aéreo, ereto ou rastejante. Folhas trifolioladas, pinaticompostas ou palmaticompostas, ausência ou presença de glândulas na face abaxial. Inflorescência 1-flora a plurifloras, umbela ou cimeira; flores pentâmeras, actinomorfas; cálice gamossépalo (dialissépalo em Oxalis subvillosa), presença ou ausência de glândulas, verde; corola gamopétala, branca, amarela, rosa a lilás; androceu diplostêmone, gamostêmone, heterodínamo; gineceu pentacarpelar, sincárpico; ovário súpero, placentação axial; fruto cápsula loculicida.

Chave para a identificação das espécies de Oxalis ocorrentes no Rio Grande do Sul

1. Folhas pinaticompostas ....................7. Oxalis cytisoides

$1^{\prime}$. Folhas palmaticompostas

2. Pétalas de cor amarela

3. Caule subterrâneo do tipo bulbo escamoso ou cormo (= bulbo sólido) 
4. Bulbo escamoso

20. Oxalis perdicaria

$4^{\prime}$. Cormo

5. Planta cespitosa, hirsuta, indumento esbranquiçado; inflorescência 1-flora . 5. Oxalis conorrhiza

$5^{\prime}$. Planta prostrada, tomentosa, indumento castanho dourado; inflorescência 3-5-flora . 9. Oxalis eriocarpa

3'. Caule aéreo, herbáceo

6. Folíolo de ápice inteiro, sem incisão evidente; discolor

7. Folíolo obovado, pilosidade serícea na face abaxial ..... 2. Oxalis bifrons

7'. Folíolo elíptico, pilosidade hirsuta em ambas as faces, face abaxial totalmente vermelha ou somente maculada ......

.23. Oxalis sarmentosa

6'. Folíolo de ápice obcordado; concolor

8. Sépalas livres, duas externas de base subcordada a cordada 25. Oxalis subvillosa

8'. Sépalas parcialmente unidas, de base não cordada

9. Caule com entrenós não aparentes cobertos pelas folhas fasciculadas; folíolo profundamente inciso $(4 / 5)$

..17. Oxalis myriophylla

9'. Caule com entrenós aparentes; folíolo inciso até 3/5

10. Planta estolonífera; folíolo inciso até $3 / 5$.

26. Oxalis tenerrima

10'. Planta decumbente; folíolo inciso até $2 / 5$

11. Pétalas $0,5-0,7 \mathrm{~cm}$ compr. ..6. Oxalis corniculata

11'. Pétalas maiores de $0,8 \mathrm{~cm}$ compr.

12. Inflorescência 1-flora 19. Oxalis paludosa

12'. Inflorescência 2-pluriflora.

13. Planta não densamente pilosa, não viscosa

18. Oxalis niederleinii

13'. Planta densamente pilosa, viscosa

22. Oxalis refracta

2'. Pétalas de cor branca, rosa a lilás

14. Bulbo escamoso
15. Folíolo de ápice truncado

16. Bulbo arredondado, entrenós muito próximos; bráctea (escama) externa com 3-6 nervuras; pétalas de cor rosa ........ 14. Oxalis latifolia

16 '. Bulbo alongado, entrenós afastados; bráctea (escama) externa com 3 nervuras; pétalas de cor branca

27. Oxalis triangularis

15. Folíolo de ápice obcordado

17. Folíolo com glândulas na face abaxial

18. Inflorescência 1-flora

19. Pétalas de cor branca, geralmente com borda purpúrea .24. Oxalis sellowiana var. alba

$19^{\prime}$. Pétalas de cor rosa 16. Oxalis lindneri

18'. Inflorescência 2-pluriflora

20. Folíolo mais comprido que largo

11. Oxalis geralensis

20’. Folíolo mais largo que comprido

21. Glândulas punctiformes que formam manchas polimorfas 21. Oxalis potamophila

21' Glândulas punctiformes que não formam manchas polimorfas

22. Folíolo com incisão $1 / 5-2 / 5$; bulbo escamoso 0,4-2,1cm larg. 8. Oxalis debilis

22 '. Folíolo com incisão 3/5-4/5; bulbo escamoso 0,1-0,2cm larg. 3. Oxalis bipartita

17'. Folíolo sem glândulas na face abaxial

23. Bráctea externa do bulbo com 3 nervuras, a qual se desintegra completamente com o tempo, inclusive as nervuras... 12. Oxalis hispidula

23'. Bráctea externa do bulbo com 5-9 nervuras, a qual se desintegra com o tempo, exceto as nervuras..

4. Oxalis brasiliensis

$14^{\prime}$. Cormo ou caule aéreo, curto e ereto

24. Caule aéreo, curto e ereto; folhas concentradas na base da planta 15. Oxalis linarantha

24' Cormo; folhas concentradas no ápice do caule 
25. Folíolo sem glândulas na face abaxial; planta glabra ....... 13. Oxalis lasiopetala

25'. Folíolo com glândulas na face abaxial; planta pubescente

26. Planta finamente pubescente; sépalas com 2 glândulas 1. Oxalis articulata

$26^{\prime}$. Planta densamente pubescente; sépalas com 3-5 glândulas 10. Oxalis floribunda

3.1 Oxalis articulata Savigny, Encyclopédie Méthodique, Botanique 4(2): 686-687. 1797 [1798].

\section{(Figuras 1 e 28-A)}

Erva com até $36 \mathrm{~cm}$ de altura, ereta, com tricomas glandulares. Cormo 0,7-9,6 x 0,6-5,5 cm. Folha palmaticomposta, concentrada no ápice do caule; folíolo 0,5-3,8 x 0,6-4,7 cm, obovado, ápice cordado, incisão até $2 / 5$ do folíolo, mais largo que comprido, presença de glândulas punctiformes na face abaxial que não formam manchas polimorfas, concolor, piloso ou pubescente; pecíolo 1,5-31,2 cm compr., piloso; estípula não observada. Inflorescência 2-14-flora, umbela ou cimeira; pedicelo 0,7-4,7 cm compr., piloso ou pubescente; sépala 0,3-0,6 $\mathrm{cm}$ compr., base não cordada, presença de duas glândulas, pubescente; pétala $0,8-1,9 \mathrm{~cm}$ compr., cor rosa a lilás, pubescente. Fruto 0,7-0,9 x 0,2-0,3 cm, lanceolado, glabro ou pubescente; $4-6$ sementes.

Hábitat: áreas abertas e ensolaradas como campos, cultivados ou não; áreas alagadas temporariamente; áreas alteradas como calçadas, beira de caminhos, estradas e rios.

Período de floração e frutificação: junho a março.

Distribuição no Rio Grande do Sul: Campos de Cima da Serra, Depressão Central, Encosta do Sudeste, Encosta Inferior do Nordeste, Encosta Superior do Nordeste, Missões, Planalto Médio e Serra do Sudeste.

Material selecionado: BRASIL, RIO GRANDE DO SUL, Augusto Pestana, 17.VIII.1953, Pivetta 558 (PACA); Bento Gonçalves, 06.X.1980, G. Pedralli 78 (ICN); Bom Jesus, $28^{\circ} 38^{\prime} 28,8^{\prime \prime} \mathrm{S} / 50^{\circ} 33^{\prime} 31,0^{\prime \prime}$ W, 16.II.2012, D. Grigoletto et al. 191 (SMDB); Cambará do Sul, 29 11'19,8'S/ $50^{\circ} 13^{\prime} 30,9^{\prime \prime}$ W, 15.II.2012, D. Grigoletto et al. 187 (SMDB); Canguçu, Terceiro Distrito de Canguçu, Coxilha do Fogo, Cabanha Sobrado Branco, 05.II.2004, F. J. M. Caporal 106 (ICN); Dois Irmãos, Cascata de São Miguel, 08.V.1982, M. Santos s/n (ICN 53375); Esmeralda, 07.XI.1982, S. Miotto \& E. Franco s/no (ICN 64899); Esteio, 23.III.1949, B. Rambo s $/ \mathrm{n}^{\circ}$ (PACA 36520); General Câmara, Santo Amaro, 05.VI.1996, A. M. Carneiro 684 (ICN); Montenegro, RS240, Km 32, 14.II.2012, D. Grigoletto et al. 172 (SMDB); Pareci Novo, 03.X.1945, B. Rambo s/n (PACA 48983); Pelotas, 18.X.2011, D. Grigoletto et al. 154 (SMDB); Porto Alegre, 14.IX.1992, I. I. Boldrini et al. 1071 (ICN); Santa

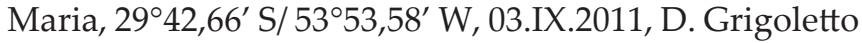

et al. 79 (SMDB); Santo Ângelo, Cristo Rei, 10.III.1950, B. Rambo s/n $n^{\circ}$ (PACA 46207); São Francisco de Paula, $29^{\circ} 22^{\prime} 29,3^{\prime \prime}$ S/ 50 $25^{\prime} 36,3^{\prime \prime}$ W, 15.II.2012, D. Grigoletto et al. 180 (SMDB); São João do Polêsine, Vale Vêneto, 15.IX.1954, A. Sehnem 1288 (PACA 104480); Viamão, 07.IX.2010, P. J. S. Silva Filho 652 (ICN).

\subsection{Oxalis bifrons Progel, Flora Brasiliensis} 12(2): 495, t. 105, f. 2.1877.

\section{(Figuras 2 e 28-B)}

Erva com até $33 \mathrm{~cm}$ de altura, prostrada, com tricomas glandulares. Caule aéreo, reptante, enraizado nos nós, entrenós aparentes. Folha palmaticomposta, insertas ao longo do caule; folíolo 1,3-3,9 x 0,8-2,8 cm, obovado, ápice arredondado, inteiro a retuso, mais comprido que largo, ausência de glândulas punctiformes na face abaxial, discolor, pubescente na face adaxial e densamente seríceo na face abaxial; pecíolo 1,6-28 cm compr., hirsuto e pubescente; estípula $0,3 \mathrm{~cm}$ compr., estreitando-se para o ápice, ápice cuneado. Inflorescência 2-8-flora, cimeira; pedicelo 0,9-1,5 cm compr., hirsuto e pubescente; sépala 0,3-0,4 cm compr., base não cordada, ausência de glândulas, serícea; pétala 1-1,6 cm compr., cor amarela, pubescente. Fruto 0,5 x 0,4 cm, globoso, pubescente; 1 semente.

Hábitat: áreas abertas e ensolaradas como campos; áreas alteradas como beira de caminhos e estradas. Vegeta em solo arenoso seco, com afloramento rochoso ou não.

Período de floração e frutificação: abril a fevereiro.

Distribuição no Rio Grande do Sul: Campos de Cima da Serra, Depressão Central, Litoral e Missões.

Material selecionado: BRASIL, RIO GRANDE DO SUL, Arroio dos Ratos, Fazenda Faxinal, 14.X.1979, K. Hagelund s/nº (ICN 106818); Cambará do Sul, 21.IX.1979, K. Hagelund s/nº (ICN 106814); Osório, IX.1958, B. Rambo s/nº (PACA 61453); Palmares do Sul, 01.X.2010, I. Boldrini 1688 (ICN); Santiago, Flórida, 30.X.2011, T. Canto-Dorow 1236 (SMDB); Torres, Butiazal, 28.IV.1986, K. Hagelund $s / n^{\circ}$ (ICN 106868).

3.3 Oxalis bipartita A. St.-Hil., Flora Brasiliae Meridionalis (quarto ed.) 1: 125, pl. 25. 1825.

\section{(Figuras 3 e 28-C)}

Erva com até $38 \mathrm{~cm}$ de altura, ereta, sem tricomas glandulares. Bulbo escamoso 0,5-1,7 x 0,1-0,2 cm, arredondado, entrenós muito próximos; bráctea externa com 3 nervuras. Folha palmaticomposta, concentrada no ápice do caule; folíolo 0,2-3 x 0,3-5,7 cm, obovado, ápice cordado, incisão de 3/5-4/5 do folíolo, mais largo que comprido, presença de glândulas punctiformes na face abaxial que não formam manchas polimorfas, concolor, glabro ou piloso; pecíolo 6-24,4 cm compr., glabro ou piloso; estípula não observada. Inflorescência 2-18-flora, cimeira; pedicelo 0,7-3 cm compr., glabro; sépala 0,2-0,6 cm compr., base não cordada, presença 
de duas glândulas, glabra; pétala 0,9-2,3 cm compr., cor rosa a lilás, glabra. Fruto 0,5-1,7 x 0,1-0,2 cm, lanceolado, glabro; 7-9 sementes.

Hábitat: áreas abertas e ensolaradas como campos, cultivados ou não; áreas sombreadas como beira de mato; áreas alteradas como beira de caminhos e estradas.

Período de floração e frutificação: junho a dezembro.

Distribuição no Rio Grande do Sul: Alto Uruguai, Campanha, Campos de Cima da Serra, Depressão Central, Encosta do Sudeste, Encosta Inferior do Nordeste, Encosta Superior do Nordeste, Litoral, Missões, Planalto Médio e Serra do Sudeste.

Material selecionado: BRASIL, RIO GRANDE DO SUL, Arroio dos Ratos, Fazenda Faxinal, 07.X.1984, K. Hagelund s/n $\mathrm{n}^{\circ}$ (ICN 106851); Augusto Pestana, 05.XI.1953, Pivetta 554 (PACA 56124); Bom Jesus, 14.X.2004, I. Boldrini et al. 1426 (ICN); Caçapava do Sul, 30.X.1974,A. M. Girardi s/n (ICN 26332); Canguçu, terceiro Distrito de Canguçu, Coxilha do Fogo, Cabanha Sobrado Branco, 03.X.2004, F. J. M. Caporal s/nº (ICN 142630); Capivari do Sul, 20.X,2001, E. N. Garcia 520 (ICN); Carazinho, 24.IX.1974, Grupo de trabalho MA/AS/RS s/nº (PEL 8925); Caxias do Sul, 26.XI.2006, I. Boldrini 1654 (ICN); Charqueadas, 20.IX.1975, sem coletor (ICN 106848); Esmeralda, 07.IX.1982, S. Miotto \& E. Franco s/nº (ICN 64901); Farroupilha, 25.X.1957, Camargo 2208 (PACA); General Câmara, Santo Amaro, 05.VI.1996, A. M. Carneiro 695 (ICN); Giruá, Granja Sodal, 12.X.1966, sem coletor (ICN 106838); Guaíba, Fazenda São Maximiano, 12.X.2007, L. F. Lima 625 (ICN); Lajeado, 26.IX.1975, sem coletor (ICN 106860); Lavras do Sul, 25.VII.1982, M. L. Porto 2881 (ICN); Nova Petrópolis, 21.IX.2004, P. M. Krauspenhar s/n $\mathrm{n}^{\circ}$ (PACA 88227); Novo Hamburgo, 02.IX.1949, B. Rambo s/n ${ }^{\circ}$ (PACA 43213); Pareci Novo, 07.VII.1954, B. Rambo s/n ${ }^{\circ}$ (PACA 42447); Passo Fundo, 11.VIII.1972, J. F. M. Valls 2131 (ICN); Pelotas, 22.IX.1967, E. C. Santos 17 (PEL); Porto Alegre, Morro São Pedro, 17.IX.2005, R. Setubal \& G. Seger 353 (ICN); Restinga Seca, Santuário, 25.IX.2011, D. Grigoletto 129 (SMDB); Rio Grande, Estação Ecológica do Taim, 10.VII.1986, J. A. Jarenkow 392 (PEL); Rosário do Sul, 30 $18,61^{\prime} \mathrm{S} / 54^{\circ} 58^{\prime} \mathrm{W}$, 03.IX.2011, D. Grigoletto et al. 89 (SMDB); Santa Maria, $29^{\circ} 42,66^{\prime}$ S $/ 53^{\circ} 53,58^{\prime}$ W, 03.IX.2011, D. Grigoletto et al. 78 (SMDB); Santana do Livramento, BR 290, 03.IX.2011, D. Grigoletto et al. 95 (SMDB); Santo Ângelo, Granja Piratini, 23.IX.1976, sem coletor (ICN 106849); São Francisco de Assis, 26.IX.2009, W. Heberle s/n (ICN 159150); São Francisco de Paula, 30.X.2005, A. Leonhardt \& M. L. Lorscheitter s $/ \mathrm{n}^{\circ}$ (ICN 126440); São João do Polêsine, Vale Vêneto, 30.IX.1944, A. Sehnem 1320 (PACA); São Leopoldo, 02.X.1946, E. Henz s/nº (PACA 35354); São Pedro do Sul, 07.X.2011, D. Grigoletto et al. 142 (SMDB); São Sepé, 16.IX.2011, D. Grigoletto et al. 116 (SMDB); São Sebastião do Caí, 07.X.1945, Schultz 416 (ICN); Silveira Martins, 05.X.2010, D. Grigoletto 7 (SMDB); Viamão, Bairro Tarumã, 07.IX.2010, P. J. S. Silva Filho 650 (ICN).

\subsection{Oxalis brasiliensis G. Lodd., Botanical Ca-} binet; 20: t. 1962. 1833.

\section{(Figuras 4 e 28-D)}

Erva com até $23 \mathrm{~cm}$ de altura, ereta, sem tricomas glandulares. Bulbo escamoso 0,6-1,5 x 0,5-1,2 cm, arredondado, entrenós muito próximos; bráctea externa com 5-9 nervuras. Folha palmaticomposta, concentrada no ápice do caule, folíolo $0,6-1,9 \times 0,8-2,2 \mathrm{~cm}$, obovado, ápice cordado, incisão até $1 / 5$ do folíolo, mais largo que comprido, ausência de glândulas punctiformes na face abaxial, concolor, adpresso pubescente; pecíolo 3,3-14,3 cm compr., adpresso pubescente; estípula não observada. Inflorescência 1-2-flora, umbela; pedicelo 0,6-4 cm compr., adpresso pubescente; sépala 0,5-0,8 $\mathrm{cm}$ compr., base não cordada, ausência ou presença de duas glândulas, glabra ou adpressa pubescente; pétala 0,9-2,2 cm compr., cor rosa, glabra ou adpressa pubescente. Fruto 0,9-1,3 x 0,1-0,2 cm, lanceolado, adpresso pubescente; 7-20 sementes.

Hábitat: áreas abertas e ensolaradas como campos; áreas alteradas como beira de caminhos e estradas. Vegeta em solos secos ou úmidos.

Período de floração e frutificação: junho a dezembro.

Distribuição no Rio Grande do Sul: Campanha, Campos de Cima da Serra, Depressão Central, Encosta do Sudeste, Encosta Inferior do Nordeste e Litoral.

Material selecionado: BRASIL, RIO GRANDE DO SUL, Arroio dos Ratos, Fazenda Faxinal, 07.X.1984, K. Hagelund s $/ \mathrm{n}^{\circ}$ (ICN 106832); Bom Jesus, Fazenda Três Marias, 14.VII.2009, R. Trevisan s/n (ICN 164763); Cristal, Fazenda Ouro Verde, 28.IX.2005, A. Guglieri et al. 546 (ICN); Esmeralda, 07.IX.1982, S. Miotto \& E, Franco et al. s/nº (ICN 64898); Guaíba, Fazenda São Maximiano, 04.VII.2010, R. Trevisan 2010 (ICN); Novo Hamburgo, Lomba Grande, 11.IX.2001, M. S. Shonordie s/n ${ }^{\circ}$ (PACA 94557); Osório, 05.IX.1950, B. Rambo s/nº (PACA 48780); Pareci Novo, 17.VIII.1949, B. Rambo s/nº (PACA 42987); Porto Alegre, Morro da Polícia, 14.IX.1992, I. I. Boldrini et al. 1075 (ICN); Quaraí, 28.IX.1984, B. Irgang et al. s/ $\mathrm{n}^{\circ}$ (ICN 92635); Rio Grande, Estação Ecológica do Taim, 16.VII.1986, J. A. Jarenkow et al. 396 (PEL); Santa Maria, Camobi, UFSM, 29.IX.2010, D. Grigoletto et al. 17 (SMDB); Santana do Livramento, BR 290, 03.IX.2011, D. Grigoletto et al. 92 (SMDB); São Pedro do Sul, 07.X.2011, D. Grigoletto et al. 145 (SMDB); São Sepé, 16.IX.2011, D. Grigoletto et al. 115 (SMDB); Viamão, Bairro Tarumã, 30.VII.2009, P. J. S. Silva Filho 426 (ICN).

\subsection{Oxalis conorrhiza Jacq., Oxalis. Monogra-} phia, Iconibus Illustrata 26. 1794.

\section{(Figuras 5e 28-E)}

Erva com até $14 \mathrm{~cm}$ de altura, cespitosa, com tricomas não glandulares de cor esbranquiçada. Cormo 0,3-2,7 x 0,9-2 cm e caule aéreo, ereto, entrenós curtos, nós próximos. Folha palmaticomposta, concentrada no 
ápice do caule; folíolo 0,5-1,2 × 0,5-1,5 cm, obovado, ápice cordado, incisão até $2 / 5$ do folíolo, mais largo que comprido, ausência de glândulas punctiformes na face abaxial, concolor, glabro ou hirsuto na face adaxial e densamente hirsuto na face abaxial; pecíolo 1,5-7 cm compr., densamente hirsuto; estípula 0,3-0,5 cm compr., largura uniforme, ápice truncado ou truncado-cuneado. Inflorescência 1-flora; pedicelo 0,7-2,8 cm compr., densamente hirsuto; sépala $0,5-0,8 \mathrm{~cm}$ compr., base não cordada, ausência de glândulas, densamente hirsuta; pétala 1,1-1,8 cm compr., cor amarela, glabra. Fruto 0,50,9 x 0,3-1 cm, ovado, pubescente; $1-3$ sementes.

Hábitat: áreas abertas e ensolaradas como campos; áreas alteradas como beira de caminhos e estradas. Vegeta em solo arenoso, seco, pedregoso ou não.

Período de floração e frutificação: agosto a abril.

Distribuição no Rio Grande do Sul: Alto Uruguai, Campanha, Depressão Central, Encosta do Sudeste, Encosta Inferior do Nordeste, Missões e Planalto Médio.

Material selecionado: BRASIL, RIO GRANDE DO SUL, Arroio dos Ratos, Granja Faxinal, 21.IX.1976, sem coletor (ICN 106944); Augusto Pestana, 19.II.1954, Pivetta 555 (PACA); Camaquã, 08.X.1977, S. Miotto 539 (ICN); Canela, Caracol, 31.I.1973, J. Jung s/n (ICN 21969); Cruz Alta, 13.XI.1974, L. Arzivenco s/nº (ICN 45392); Giruá, Granja Sodal, 09.XI.1966, sem coletor (ICN 106837); Guaíba, Fazenda São Maximiano, 12.III.2006, L. F. Lima 306 (ICN); Itaara, 20.IX.2011, D. Grigoletto et al. 117 (SMDB); Palmeira das Missões, 03.XII.2011, D. Grigoletto et al. 164 (SMDB); Pelotas, 06.XII.1951, J. Gomes s/nº (PEL 1049); Portão, 27.XI.1935, B. Rambo s/n (PACA 2135); Porto Alegre, Morro do Osso, 11.XI.2003, F. Cruz s/n ${ }^{\circ}$ (ICN 119223); Quaraí, 28.IX.1984, B. Irgang et al. s/nº (ICN 92766); Santa Bárbara do Sul, 24.X.1974, L. Arzivenco et al. s/n ${ }^{\circ}$ (ICN 42281); Santa Maria, Camobi, Faixa Nova, 22.III.2012, D. Grigoletto et al. 205 (SMDB); Santana do Livramento, Fazenda Vento Aragano, 09.XI.2008, R. Trevisan \& I. Boldrini 1005 (ICN); Santa Rosa, 03.II.1971, M. L. Porto \& P. L. Oliveira $\mathrm{s} / \mathrm{n}^{\circ}$ (ICN 9656); Santiago, 12.X.2011, D. Grigoletto et al. 150 (SMDB); Santo Ângelo, 20.VIII.1975, sem coletor (ICN 106855); São Francisco de Assis, 27.IX.2009, E. Freitas 560 (ICN); São Pedro do Sul, 07.X.2011, D. Grigoletto et al. 138 (SMDB); Uruguaiana, 12.X.1974, M. L. Pôrto 927 (ICN); Viamão, 24.III.1976, S. Miotto 1 (ICN).

3.6 Oxalis corniculata L., Species Plantarum 1: 435. 1753. (1 May 1753)

\section{(Figuras 6 e 28-F)}

Erva com até $32 \mathrm{~cm}$ de altura, decumbente, sem tricomas glandulares. Caule aéreo, ereto, entrenós aparentes. Folha palmaticomposta, insertas ao longo do caule; folíolo 0,4-1,7 x 0,4-2,3 cm, obovado, ápice cordado, incisão até 2/5 do folíolo, mais largo que comprido, ausência de glândulas punctiformes na face abaxial, concolor, glabro na face adaxial e adpresso pubescente na face abaxial; pecíolo 1-6,5 cm compr., pubescente; estípula 0,2-0,3 cm compr., largura uniforme, ápice truncado. Inflorescência 1-8-flora, umbela ou cimeira; pedicelo $0,5-1 \mathrm{~cm}$ compr., pubescente; sépala 0,3-0,4 cm compr., base não cordada, ausência de glândulas, pubescente; pétala $0,5-0,7 \mathrm{~cm}$ compr., cor amarela, glabra. Fruto 0,8-1,9 x 0,2-0,3 cm, lanceolado, pubescente; 5-11 sementes.

Hábitat: áreas abertas, alteradas e ensolaradas como beira de caminhos, estradas, jardins, calçadas e terrenos baldios.

Período de floração e frutificação: julho a abril.

Distribuição no Rio Grande do Sul: Alto Uruguai, Campanha, Campos de Cima da Serra, Depressão Central, Encosta do Sudeste, Encosta Inferior do Nordeste, Litoral, Planalto Médio e Missões.

Material selecionado: BRASIL, RIO GRANDE DO SUL, Augusto Pestana, 30.VIII.1953, Pivetta 560 (PACA); Cambará do Sul, I.2005, K. T. Bottega Kerber s/nº (PACA 103563); Canela, 14.II.2012, D. Grigoletto et al. 179 (SMDB); Cruz Alta, 16.II.2012, D. Grigoletto et al. 194 (SMDB); Giruá, 09.XI.1966, sem coletor (ICN 106829); Gramado, 07.I.2012, D. Grigoletto 166 (SMDB); Itaqui, 29 $24^{\prime} 27,8^{\prime \prime}$ S/ $50^{\circ} 10^{\prime} 31,7^{\prime \prime}$ W, 15.II.2012, D. Grigoletto et al. 185 (SMDB); Montenegro, RS240, Km 32, 14.II.2012, D. Grigoletto et al. 171 (SMDB); Nova Petrópolis, 07.I.2012, D. Grigoletto 165 (SMDB); Pelotas, 12.XII.1957, Sacco 849 (PACA); Picada Café, 29 $29^{\prime} 34^{\prime \prime} \mathrm{S} / 51^{\circ} 09^{\prime} 10,6^{\prime \prime} \mathrm{W}$, 14.II.2012, D. Grigoletto et al. 174 (SMDB); Portão, 14.II.2012, D. Grigoletto et al. 173 (SMDB); Porto Alegre, 03.IX.1977, Longhi \& Born s/ $n^{\circ}$ (ICN 34979); Restinga Seca, Santuário, 25.IX.2011, D. Grigoletto 125 (SMDB); Santa Maria, Centro, 10.XI.2011, D. Grigoletto et al. 157 (SMDB); São Francisco de Paula, Tainhas, 17.II.1946, B. Rambo s/n (PACA 32299); São Leopoldo, 1907, F. Theissen s/nº (PACA 7375); Tenente Portela, Salto do Yucumã, 10.VII.1981, B. Irgang s/nº (ICN 93690); Torres, 16.I.1967, sem coletor (ICN 106828); Vacaria, $28^{\circ} 20^{\prime} 28,5^{\prime \prime} \mathrm{S} / 50^{\circ} 54^{\prime} 03,2^{\prime \prime} \mathrm{W}, 16 . \mathrm{II} .2012$, D. Grigoletto et al. 192 (SMDB); Viamão, bairro Tarumã, 07.IX.2010, P. J. S. Silva Filho 653 (ICN).

3.7 Oxalis cytisoides C. Mart. \& Zucc., Denkschriften der Königlichen Akademie der Wissenschaften zu Muenchen 9: 178. 1825.

(Figuras 7 e 28-G)

Subarbusto com até $85 \mathrm{~cm}$ de altura, ereto, sem tricomas glandulares. Caule aéreo, ereto, entrenós aparentes. Folha pinaticomposta, insertas ao longo do caule; folíolo 0,8-4,7 x 0,4-2,3 cm, lanceolado, ápice agudo, inteiro, mais comprido que largo, ausência de glândulas punctiformes na face abaxial, concolor, pubescente; pecíolo 1,4-5,1 cm compr., pubescente; estípula $0,05 \mathrm{~cm}$ compr., largura uniforme, ápice truncado. Inflorescência 5-7-flora, cimeira; pedicelo 0,2-1,2 cm compr., pubescente; sépala 0,3-0,4 cm compr., base não cordada, ausência de glândulas, pubescente; pétala $0,5-0,7 \mathrm{~cm}$ compr., cor rosa a branca, glabra. Fruto 0,4-0,6 x 0,3-0,5 cm, amplamente 
ovado, pubescente; 2 sementes.

Hábitat: áreas fechadas e sombreadas como beira de matos.

Período de floração e frutificação: novembro a abril.

Distribuição no Rio Grande do Sul: Alto Uruguai.

Material selecionado: BRASIL, RIO GRANDE DO SUL, Derrubadas, Salto do Yucumã, 03.XII.2011, D. Grigoletto et al. 162 (SMDB); Marcelino Ramos, 02.IV.1988, J. A. Jarenkow 847 (PEL).

\subsection{Oxalis debilis Kunth, Nova Genera et Spe-} cies Plantarum (quarto ed.) 5: 236. 1821[1822].

\section{(Figura 8)}

Erva com até $28 \mathrm{~cm}$ de altura, ereta, sem tricomas glandulares. Bulbo escamoso 0,4-2,2 x 0,4-2,1 cm, arredondado, entrenós muito próximos; bráctea externa com 3 nervuras. Folha palmaticomposta, concentrada no ápice do caule, folíolo 0,5-3,2 x 0,3-3,8 cm, obovado, ápice cordado, incisão até $2 / 5$ do folíolo, mais largo que comprido, presença de glândulas punctiformes na face abaxial que não formam manchas polimorfas, concolor, piloso; pecíolo 10,7-25,7 cm compr., densamente hirsuto, estípula não observada. Inflorescência 4-9-flora, cimeira; pedicelo 1,4-3,1 cm compr., hirsuto; sépala $0,4-0,6 \mathrm{~cm}$ compr., base não cordada, presença de duas glândulas, pilosa; pétala 1,2-1,5 cm compr., cor rosa, glabra. Fruto $0,9 \times 0,2 \mathrm{~cm}$, lanceolado, glabro ou piloso; 8 sementes.

Hábitat: ambientes alterados como áreas cultivadas, jardins, beira de caminhos e estradas.

Data de floração e frutificação: junho a fevereiro.

Distribuição no Rio Grande do Sul: Alto Uruguai, Depressão Central, Encosta Superior do Nordeste e Litoral.

Material selecionado: BRASIL, RIO GRANDE DO SUL, Caxias do Sul, 03.XII.1946, B. Rambo s/nº (PACA 44586); General Câmara, Santo Amaro, 05.VI.1996, A. M. Carneiro 685 (ICN); Guaíba, 24.IX.1984, K. Hagelund $\mathrm{s} / \mathrm{n}^{\circ}$ (ICN 106876); Itati, $29^{\circ} 27^{\prime} 0,79^{\prime \prime} \mathrm{S} / 50^{\circ} 0,7^{\prime} 43,2^{\prime \prime} \mathrm{W}$, 15.II.2012, D. Grigoletto et al. 184 (SMDB); Porto Mauá, 01.X.1975, sem coletor (ICN 106875); Porto Alegre, Rua José Alencar, 21.IX.1976, L. Arzivenco s/nº (ICN 50295); Santa Maria, Centro, 06.X.2011, D. Grigoletto et al. 133 (SMDB); Veranopólis, 16.IX.1971, J. C. Lindeman \& B. E. Irgang s/nº (ICN 8109); Viamão, 07.IX.2010, P. J. S. Silva Filho 651 (ICN).

\subsection{Oxalis eriocarpa DC., Annales des Sciences} Naturelles (Paris) 4: 23.1825 (Jan 1825).

\section{(Figuras 9 e 28-H)}

Erva com até $16 \mathrm{~cm}$ de altura, rastejante, com tricomas glandulares e não glandulares de cor castanha. Cormo $2-7,5 \times 0,9-2 \mathrm{~cm}$. Folha palmaticomposta, insertas ao longo do caule; folíolo 0,5-2,3 x 0,5-2,6 cm, obovado, ápice arredondado ou cordado, inteiro ou retuso, mais largo que comprido, ausência de glândulas punctiformes na face abaxial, concolor, tomentoso; pecíolo 1,5-13,3 cm compr., pubescente e tomentoso; estípula 0,2 cm compr., estreitando-se para o ápice, ápice agudo. Inflorescência 3-5-flora, umbela ou cimeira; pedicelo 0,5-1,1 cm compr., pubescente e tomentoso; sépala 0,4-0,5 cm compr., base não cordada, ausência de glândulas, tomentosa; pétala $1-1,8 \mathrm{~cm}$ compr., cor amarela, pilosa. Fruto 0,3-0,5 x 0,60,9 cm, globoso, tomentoso; 1 semente.

Hábitat: áreas abertas e ensolaradas como campos; geralmente em barrancos. Também ocorre em áreas alteradas como beira de caminhos e estradas.

Período de floração e frutificação: junho a fevereiro.

Distribuição no Rio Grande do Sul: Alto Uruguai, Campanha, Depressão Central, Encosta do Sudeste, Missões, Planalto Médio e Serra do Sudeste.

Material selecionado: BRASIL, RIO GRANDE DO SUL, Alegrete, Cerro do Tigre, 27.IX.2008, W. Heberle $\mathrm{s} / \mathrm{n}^{\circ}$ (ICN 157304); Arroio dos Ratos, Fazenda Faxinal, 07.X.1984, K. Hagelund s/n (ICN 106883); Cacequi, 28.IX.1983, J. Mariath s/n (ICN 66648); Caçapava do Sul, 05.II.1975, K. Hagelund s/nº (ICN 106888); Camaquã, 26.IX.1980, B. Irgang et al. s/n (ICN 92751); Canguçu, Terceiro Distrito de Canguçu, Coxilha do Fogo, Cabanha Sobrado Branco, 03.X.2004, F. J. M. Caporal s/n ${ }^{\circ}$ (ICN 145347); Canoas, 08.IX.1935, B. Rambo s/nº (PACA 1075); Cerro Largo, IX.1944, E. Friderichs s/n (PACA 26743); Cruz Alta, 2.X.1971, J. C. Lindeman et al. s/n (ICN 8237); Encruzilhada do Sul, 02.X.1984, M. Sobral \& Y. Folz 3056 (ICN); Esteio, 01.VI.1954, B. Rambo s/nº (PACA 41789); Giruá, Granja Sodal, 30.X.1966, sem coletor (ICN 106886); Guaíba, Fazenda São Maximiano, 12.X.2007, L. F. Lima 628 (ICN); Lavras do Sul, 17.X.1971, J. C. Lindeman \& B. Irgang $\mathrm{s} / \mathrm{n}^{\circ}$ (ICN 8664); Manoel Viana, Fazenda Miracatu, 15.IX.2006, E. Freitas 9 (ICN); Pareci Novo,18.VII.1949, B. Rambo s/n ${ }^{\circ}$ (PACA 42602); Piratini, 15.XI.1975, L. Arzivenco $\mathrm{s} / \mathrm{n}^{\circ}$ (ICN 48581); Porto Alegre, Morro São Pedro, 02.VIII.2006, R. Setubal 273 (ICN); Rosário do Sul, $30^{\circ} 13,83^{\prime} \mathrm{S} / 54^{\circ} 44,26^{\prime} \mathrm{W}$, 03.IX.2011, D. Grigoletto et al. 84 (SMDB); Santa Bárbara do Sul, 24.X.1974, L. Arzivenco et al. s/n ${ }^{\circ}$ (ICN 42261); Santa Maria, Estância do Minuano, 13.X.2011, D. Grigoletto et al. 146 (SMDB); Santiago, 22.X.2011, D. Grigoletto et al. 153 (SMDB); Santana Livramento, 14.X.1974, M. L. Porto 987 (ICN 26250); Santo Ângelo, Granja Piratini, 20.VIII.1975, sem coletor (ICN 106882); São Francisco de Assis, sem data, sem coletor (ICN 106884); São Pedro do Sul, 07.X.2011, D. Grigoletto et al. 140 (SMDB); São Sepé, 02.X.1988, M. Rossato et al. s/nº (HUCS 4545); Tupanciretã, 24.I.1942, B. Rambo s/n (PACA 9919); Viamão, Parque St. Hilaire, 06.X.1979, J. L. Waechter 1407 (ICN).

\subsection{Oxalis floribunda Lehm., Semina in Horto Botanico Hamburgensi 17. 1826.}

(Figuras 10 e 28-I)

Erva com até $35 \mathrm{~cm}$ de altura, ereta, sem tricomas glandulares. Cormo 1,1-5,9 x 0,8-5,5 cm. Folha palmaticomposta, concentrada no ápice do caule; folíolo 0,7-3,9 
x 0,7-4,9 cm, obovado, ápice cordado, incisão até $3 / 5$ do folíolo, mais largo que comprido, presença de glândulas punctiformes na face abaxial que não formam manchas polimorfas, concolor, pubescente ou velutino; pecíolo 3,7-28 cm compr., pubescente ou velutino; estípula não observada. Inflorescência 3-10-flora, umbela; pedicelo 1-2,6 cm compr., pubescente ou velutino; sépala 0,3-0,6 $\mathrm{cm}$ compr., base não cordada, presença de três a cinco glândulas, pubescente a velutina; pétala $0,4-1,6 \mathrm{~cm}$ compr., cor rosa a lilás, glabra, pubescente a velutina. Fruto 0,6-1,1 x 0,2-0,4 cm, lanceolado, pubescente ou velutino; 5-10 sementes.

Hábitat: áreas abertas e ensolaradas como campos, cultivados ou não; áreas alagadas temporariamente; áreas alteradas como beira de caminhos e estradas.

Período de floração e frutificação: junho a abril.

Distribuição no Rio Grande do Sul: Alto Uruguai, Campanha, Campos de Cima da Serra, Depressão Central, Encosta do Sudeste, Encosta Inferior do Nordeste, Litoral, Missões, Planalto Médio e Serra do Sudeste.

Material selecionado: BRASIL, RIO GRANDE DO SUL, Arroio dos Ratos, Fazenda Faxinal, 14.III.1980, K. Hagelund s/n (ICN 106864); Canguçu, Esteio, 11.XI.1955, B. Rambo s/n (PACA 57148); Giruá, Jari, 26.I.1942, B. Rambo s/n (PACA 9167); Lavras do Sul, 11.XI.2006, L. P. Queiroz \& M. C. Machado 12370 (PACA); Panambi, 23.IX.2011, D. Grigoletto et al. 120 (SMDB); Pelotas, 20.X.1945, J. R. Swallen 7039 (PEL); Porto Alegre, VI.1945, B. Rambo s/n (PACA 30134); Restinga Seca, Santuário, 25.IX.2011, D. Grigoletto 128 (SMDB); Rosário do Sul, 30¹3,83'S/ 54²44,26’ W, 03.IX.2011, D. Grigoletto et al. 86 (SMDB); Santa Maria, Camobi, UFSM, 15.IX.2011, D. Grigoletto et al. 98 (SMDB); Santo Ângelo, Granja Piratini, 23.IX.1976, sem coletor (ICN 106857); São Francisco de Paula, Tainhas, 16.II.1946, B. Rambo s/n (PACA 32269); São Leopoldo, 1907, F. Theiben s/nº (PACA 7371); São Pedro do Sul, 07.X.2011, D. Grigoletto et al. 135 (SMDB); Taquari, 14.XII.1957, B. Rambo s/n (PACA 61520); Torres, 12.XI.1954, B. Rambo s/n (PACA 56232); Uruguaiana, 12.X.1974, M. L. Porto 929 (ICN); Vacaria, 29²6'45,2”S/

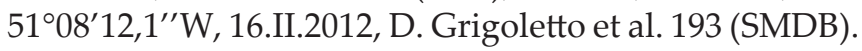

\subsection{Oxalis geralensis R. Knuth, Repertorium} Specierum Novarum Regni Vegetabilis 23: 281. 1927.

\section{(Figura 11)}

Erva com até $34 \mathrm{~cm}$ de altura, ereta, sem tricomas glandulares. Bulbo escamoso 0,2-0,5 x 0,2 cm, arredondado, entrenós muito próximos; bráctea externa com 3 nervuras. Folha palmaticomposta, concentrada no ápice do caule; folíolo 2-4,8 x 0,5-2,7 cm, obovado, ápice cordado, incisão até $1 / 5$ do folíolo, mais comprido que largo, ausência ou presença de glândulas punctiformes na face abaxial que não formam manchas polimorfas, concolor, glabra; pecíolo 7,2-19,2 cm compr., glabro; estípula não observada. Inflorescência 3-7-flora, cimeira; pedicelo 1,4-3,8 cm compr., glabro; sépala 0,3-0,4 x 0,1$0,15 \mathrm{~cm}$, base não cordada, presença de duas glândulas, glabra; pétala 1,4 cm compr., cor rosa a branca, glabra. Fruto não observado.

Hábitat: locais sombreados como beira de mato. Vegeta em solos pedregosos.

Período de floração: dezembro a fevereiro.

Distribuição no Rio Grande do Sul: Campos de Cima da Serra e Litoral.

Material selecionado: BRASIL, RIO GRANDE DO SUL, Cambará do Sul, II.1948, B. Rambo s/n (PACA 36522); Itati, 06.XII.1990, M. R. Ritter 570 (SMDB); Osório, sem data, J. C. Lindeman et al. s/n (ICN 20850); Torres, 01.I.1954, B. Rambo s/n (PACA 54707).

3.12 Oxalis hispidula Zucc., Denkschriften der Königlichen Akademie der Wissenschaften zu Muenchen 9: 143. 1825.

(Figuras 12 e 28-J)

Erva com até $12 \mathrm{~cm}$ de altura, ereta, sem tricomas glandulares. Bulbo escamoso 0,5-1 x 0,4-1 cm, arredondado, entrenós muito próximos; bráctea externa com 3 nervuras. Folha palmaticomposta, concentrada no ápice do caule, folíolo 0,3-1 x 0,4-1 cm, obovado, ápice cordado, incisão até $1 / 5$ do folíolo, mais largo que comprido, ausência de glândulas punctiformes na face abaxial, concolor, glabro ou escassamente piloso na margem; pecíolo 1-10,2 cm compr., glabro; estípula não observada. Inflorescência 1-flora ou raramente 2-flora, cimeira; pedicelo 0,8-5 cm compr., glabro; sépala 0,4-0,5 cm compr., base não cordada, presença de uma ou duas glândulas, glabra; pétala 1,3-1,6 cm compr., cor rosa a lilás, glabra. Fruto 0,6-0,9 x 0,2 cm, lanceolado, glabro; 9 sementes.

Hábitat: áreas abertas e ensolaradas como campos; em solos secos ou úmidos.

Data de floração e frutificação: março a dezembro.

Distribuição no Rio Grande do Sul: Campanha, Depressão Central, Encosta do Sudeste, Encosta Superior do Nordeste, Litoral, Missões, Planalto Médio e Serra do Sudeste.

Material selecionado: BRASIL, RIO GRANDE DO SUL, Caçapava do Sul, Boa Vista, 07.III.2012, D. Grigoletto et al. 197 (SMDB); Farroupilha, 10.VI.1975, L. Amaral et al. s/n (ICN 29462); Passo Fundo, 22.VIII.1974, Grupo de trabalho MA/AS/RS s/n (PEL 8132); Pelotas, 06.XI.1894, J. D. P. Bandeira s/n (PEL 11389); Porto Alegre, Morro São Pedro, 03.IX.2005, R. Setubal 354 (ICN); Quaraí, 29.IV.2010, I. Boldrini et al. 1649 (ICN); Rio Grande, Estação Ecológica do Taim, 10.VII.1986, J. A. Jarenkow 393 (PEL); Santo Ângelo, Granja Piratini, 20.VIII.1975, sem coletor (ICN 106898); São Borja, 15.VI.1990, R. Záchia 239 (ICN); São Pedro do Sul, 07.X.2011, D. Grigoletto et al. 139 (SMDB).

3.13 Oxalis lasiopetala Zucc., Denkschriften der Königlichen Akademie der Wissenschaften 
zu Muenchen 9: 149. 1825.

\section{(Figuras 13 e 28-K)}

Erva com até $26 \mathrm{~cm}$ de altura, ereta, sem tricomas glandulares. Cormo 0,4-3,8 x 0,6-1,8 cm. Folha palmaticomposta, concentrada no ápice do caule; folíolo 0,3-1,4 x 0,4-2,6 cm, obovado, ápice cordado, incisão até $4 / 5$ do folíolo, mais largo que comprido, ausência de glândulas punctiformes na face abaxial, concolor, glabro ou raramente piloso; pecíolo 2,2-24,6 cm compr., glabro ou piloso; estípula não observada. Inflorescência 2-8-flora, umbela; pedicelo 1,1-4,7 cm compr., piloso; sépala 0,3-0,6 cm compr., base não cordada, presença de duas glândulas, pilosa; pétala 1,2-1,7 cm compr., cor rosa, glabra. Fruto 0,5-1,5 x 0,2-0,7 cm, lanceolado, glabro; 5 -7 sementes.

Hábitat: áreas úmidas, abertas e ensolaradas como campos, cultivados ou não; áreas alagadas temporariamente; ambientes alterados como beira de caminhos e estradas.

Período de floração e frutificação: abril a outubro.

Distribuição no Rio Grande do Sul: Depressão Central, Missões e Serra do Sudeste.

Material selecionado: BRASIL, RIO GRANDE DO SUL, Arroio dos Ratos, Granja Faxinal, 07.X.1984, K. Hagelund s/n $\mathrm{n}^{\circ}$ (ICN 106897); Canguçu, Terceiro Distrito de Canguçu, Coxilha do Fogo, Cabanha Sobrado Branco, 21.IV.2005, F. J. M. Caporal s/n (ICN 142631); Guaíba, Fazenda São Maximiano, 12.X.2010, F. L. Lima 626 (ICN); Porto Alegre, Morro Santa Tereza, 13.IV.1975, L. Arzivenco s/n (ICN 42963); Restinga Seca, Santuário, 25.IX.2011, D. Grigoletto 126 (SMDB); Santa Maria, $29^{\circ} 41,23^{\prime} \mathrm{S} / 53^{\circ} 53,21^{\prime}$ W, 08.IV.2011, D. Grigoletto et al. 34 (SMDB); Santo Ângelo, Granja Piratini, 29.IX.1975, sem coletor (ICN 106900); São Francisco de Assis, 18.IV.2008, E. Freitas $488(\mathrm{ICN})$.

\subsection{Oxalis latifolia Kunth, Nova Genera et} Species Plantarum (quarto ed.) 5: 237, pl. 467. 1821[1822].

\section{(Figuras 14 e 28-L)}

Erva com até $19 \mathrm{~cm}$ de altura, ereta, sem tricomas glandulares. Bulbo escamoso 0,6-1,3 x 0,4-1,3 cm, arredondado, entrenós muito próximos; bráctea externa com 3-6 nervuras. Folha palmaticomposta, concentrada no ápice do caule; folíolo $0,8-2,7 \times 1,2-4,1 \mathrm{~cm}$, obovado, ápice truncado, incisão até $1 / 5$ do folíolo, mais largo que comprido, ausência ou presença de glândulas punctiformes na incisão que não formam manchas polimorfas, concolor, piloso na borda; pecíolo 2,6-19,1 cm compr., glabro ou piloso; estípula não observada. Inflorescência 5-11-flora, umbela; pedicelo 0,5-1,1 cm compr., glabro; sépala 0,3-0,5 cm compr., base não cordada, presença de duas glândulas, glabra; pétala 1-1,2 cm compr., cor rosa, glabra. Fruto 0,5 x 0,3 cm, ovado, glabro; 5 sementes.

Hábitat: áreas abertas, alteradas e ensolaradas como terrenos cultivados, hortas, canteiros, beira de caminhos e estradas.

Período de floração e frutificação: dezembro a fevereiro.

Distribuição no Rio Grande do Sul: Alto Uruguai, Depressão Central, Encosta Inferior do Nordeste e Litoral.

Material selecionado: BRASIL, RIO GRANDE DO SUL, Derrubadas, 03.XII.2011, D. Grigoletto et al. 159 (SMDB); Gramado, Mini-mundo, 07.I.2012, D. Grigoletto

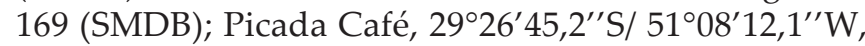
14.II.2012, D. Grigoletto et al. 178 (SMDB); Santa Maria, 08.IV.2012, D. Grigoletto et al. 208 (SMDB); Torres, 1951, sem coletor (ICN 106901).

\subsection{Oxalis linarantha Lourteig, Flora Ilustra-} da Catarinense 1: 146. 1983.

\section{(Figuras 15 e 29-A)}

Erva com até $42 \mathrm{~cm}$ de altura, ereta, com tricomas glandulares. Caule aéreo, ereto, entrenós curtos. Folha palmaticomposta, concentrada na base da planta; folíolo 1-5,4 x 0,6-6 cm, obovado, ápice cordado, incisão até $2 / 5$ do folíolo, mais largo que comprido, ausência de glândulas punctiformes na face abaxial, concolor, glabro ou hirsuto; pecíolo 2,6-37,1 cm compr., glabro ou hirsuto; estípula não observada. Inflorescência 3-10-flora, cimeira; pedicelo 1,6-6,1 cm compr., glabra ou hirsuta; sépala 0,4-0,5 cm compr., base não cordada, ausência de glândulas, glabra ou hirsuta; pétala 1,5-2,3 cm compr., cor rosa claro a lilás, glabra. Fruto 1,2-2 x 0,2 cm, lanceolado, glabro ou hirsuto; 9-11 sementes.

Hábitat: áreas fechadas e sombreadas como matos; áreas alteradas como beira de caminhos e estradas, mas sempre sombreadas.

Período de floração e frutificação: julho a fevereiro.

Distribuição no Rio Grande do Sul: Alto Uruguai, Campos de Cima da Serra, Depressão Central, Encosta do Sudeste, Encosta Inferior do Nordeste, Encosta Superior do Nordeste, Litoral, Missões, Planalto Médio e Serra do Sudeste.

Material selecionado: BRASIL, RIO GRANDE DO SUL, Arroio dos Ratos, Fazenda Faxinal, sem data, K. Hagelund s/n (ICN 106902); Augusto Pestana, 15.VIII.1953, Pivetta 559 (PACA); Cambará do Sul, Itaimbezinho, 03.II.1973, J. C. Lindeman et al. s/n (ICN 21248); Capão do Leão, 29.IX.1986, J. A. Jarenkow \& J. L. Waechter 460 (PEL); Cerro Largo, VIII.1944, E. Friderichs s/n ${ }^{\circ}$ (PACA 26745); Encruzilhada do Sul, 02.X.1984, M. Sobral \& Y. Folz 3044 (ICN); Esmeralda, 18.IX.1983, L. A. Cestaro s/nº (ICN 60032); Esteio, 24.XI.1948, B. Rambo s/n (PACA 38346); Farroupilha, 2.IX.1957, Camargo 1683 (PACA); Garibaldi, 29.X.1957, Camargo 2312 (PACA); Giruá, Granja Sodal, 29.IX.1966, sem coletor (ICN 106903); Guaíba, Fazenda São Maximiano, 04.X.2009, N. I. Matzembacher 3051 (ICN); Itati, 27.X.1974, M. L. Porto et al. 1043(ICN); Lajeado, 26.IX.1975, sem coletor (ICN 106907); Marcelino Ramos, 04.VIII.1986, J. A. Jarenkow 426 (PEL); 
Montenegro, 19.IX.1957, Camargo 1782 (PACA); Nova Petrópolis, 21.IX.2004, P. M. Krauspenhar s/n (PACA 88230); Novo Hamburgo, 22.VIII.1949, B. Rambo s/nº (PACA 43041); Osório, 11.IX.1950, B. Rambo s/n (PACA 48769); Pareci Novo, 17.IX.1949, B. Rambo s/n (PACA 42975); Pelotas, 10.IX1976, L. Arzivenco s/n (ICN 50282); Porto Alegre, 30.IX.1949, B. Rambo s/n (PACA 43650); Rolante, 07.X.1987, S. Diesel s/n (PACA 69814); Santa Maria, Boca do Monte, 04.IX.2011, D. Grigoletto et al. 97 (SMDB); Santana da Boa Vista, X.1985, M. Sobral et al. s/ $\mathrm{n}^{\circ}$ (ICN 67041); Santo Ângelo, 20.VIII.1975, sem coletor (ICN 106906); São Leopoldo, 24.IX.1951, M. S. Marchioretto \& R. B. 284 (PACA); Silveira Martins, 05.X.2010, D. Grigoletto 6 (SMDB); Taquara, 22.IX.1979, K. Hagelund $\mathrm{s} / \mathrm{n}^{\circ}$ (ICN 106854); Tavares, Parque Nacional da Lagoa do Peixe, 02.XI.2003, R. Záchia 5679 (ICN); Tenente Portela, Parque Estadual do Turvo, VIII.1981, P. Brack et al. s/n (ICN 88953); Veranopólis, VIII.1984, M. Sobral et al. s/nº (ICN 61384); Viamão, Parque Estadual Itapuã, VIII.2003, C. B. Palma s/nº (ICN 129032).

3.16 Oxalis lindneri R. Knuth, Notizbl. Bot. Gart. Berlin-Dahlem 7(67): 310. 1919.

\section{(Figuras 16 e 29-B)}

Erva com até $19 \mathrm{~cm}$ de altura, ereta, sem tricomas glandulares. Bulbo escamoso 0,5-2 x 0,4-1,3 cm, arredondado, entrenós muito próximos; bráctea externa com 3 nervuras. Folha palmaticomposta, concentrada no ápice do caule, folíolo 0,4-1,6 x 0,4-1,9 cm, obovado, ápice cordado, incisão até $2 / 5$ do folíolo, mais largo que comprido, presença de glândulas punctiformes na face abaxial que não formam manchas polimorfas, concolor, glabro ou pubescente na face abaxial; pecíolo 3,4-17,5 cm compr., glabro ou piloso; estípula não observada. Inflorescência 1-flora; pedicelo 1,7-3,7 cm compr., glabro ou piloso; sépala 0,3-0,5 cm compr., base não cordada, presença de duas glândulas, glabra ou pilosa; pétala 1,1-2,1 cm compr., cor rosa, glabra. Fruto 0,6-1 x 0,1-0,2 cm, lanceolado, glabro ou piloso; 6-10 sementes.

Hábitat: áreas abertas e ensolaradas como campos; solos úmidos e arenosos.

Data de floração e frutificação: agosto a setembro.

Distribuição no Rio Grande do Sul: Depressão Central.

Material selecionado: BRASIL, RIO GRANDE DO SUL, Santa Maria, Camobi, UFSM, 15.IX.2011, D. Grigoletto et al. 101 (SMDB); São Pedro do Sul, BR 287, Km 276, 12.VII.2011, D. Grigoletto et al. 43 (SMDB); São Sepé, 16.IX.2011, D. Grigoletto et al. 114 (SMDB).

3.17 Oxalis myriophylla A. St.-Hil., Flora Brasiliae Meridionalis (quarto ed.) 1: 121. 1825.

\section{(Figura 17)}

Erva com até $10 \mathrm{~cm}$ de altura, ereta, sem tricomas glandulares. Caule aéreo, ereto, entrenós não aparentes. Folha palmaticomposta, concentradas ao longo do caule; folíolo 0,1-0,3 x 0,1-0,2 cm, obovado, ápice cordado, incisão de $4 / 5$ do folíolo, mais largo que comprido, ausência de glândulas punctiformes na face abaxial, concolor, pubescente ou tomentoso; pecíolo 0,5-1 cm compr., pubescente ou tomentoso; estípula $0,1 \mathrm{~cm}$ compr., largura uniforme, ápice obtuso. Inflorescência 1-flora; pedicelo 0,3-0,7 cm compr., pubescente ou tomentoso; sépala 0,2 cm compr., base não cordada, ausência de glândulas, linha violácea na borda, pubescente ou tomentoso; pétala 0,3-0,4 cm compr., cor amarela, glabra. Fruto 0,2 x $0,5 \mathrm{~cm}$, ovada, pubescente ou tomentoso; 1 semente.

Hábitat: áreas abertas e ensolaradas como campos; solo pedregoso.

Período de floração e frutificação: janeiro a setembro.

Distribuição no Rio Grande do Sul: Campanha.

Material selecionado: BRASIL, RIO GRANDE DO SUL, Quaraí, Cerro do Jarau, 28.IX.1984, B. Irgang et al. s/n (ICN 92763).

3.18 Oxalis niederleinii R. Knuth, Notizblatt des Botanischen Gartens und Museums zu Berlin-Dahlem 7(67): 299. 1919.

(Figuras 18 e 29-C)

Erva com até $33 \mathrm{~cm}$ de altura, decumbente, com tricomas glandulares. Caule aéreo, ereto, entrenós aparentes. Folha palmaticomposta, insertas ao longo do caule; folíolo 0,4-1,9 x 0,4-2,2 cm, obovado, ápice cordado, incisão até 2/5 do folíolo, mais largo que comprido, ausência de glândulas punctiformes na face abaxial, concolor, hirsuto; pecíolo 1,2-6,8 cm compr., hirsuto e pubescente; estípula 0,1-0,2 cm compr., largura uniforme, ápice truncado. Inflorescência 2-9-flora, cimeira; pedicelo 0,4-1,4 cm compr., hirsuto e pubescente; sépala 0,2-0,4 cm compr., base não cordada, ausência de glândulas, hirsuto e pubescente; pétala $0,9-1,6 \mathrm{~cm}$ compr., cor amarela, pilosa. Fruto 0,4-0,6 x 0,3-0,5 cm, oblongo, hirsuto e pubescente; fruto; $2-3$ sementes.

Hábitat: áreas abertas e ensolaradas; geralmente em ambientes alterados como beira de caminhos, estradas, terrenos baldios e calçadas.

Período de floração e frutificação: julho a dezembro. Distribuição no Rio Grande do Sul: Alto Uruguai, Campanha, Depressão Central, Encosta Inferior do Nordeste, Litoral, Missões, Planalto Médio e Serra do Sudeste.

Material selecionado: BRASIL, RIO GRANDE DO SUL, Agudo, 27.IX.1985, D. Falkemberg 3333 (HUCS, ICN, PACA, PEL); Augusto Pestana,17. IX.1953, R. Reitz 556 (PACA); Canguçu, 01.XI.1997, E. N. Garcia \& J. A. Jarenkow 211 (PEL); Cerro Largo, VIII.1944, E. Friderichs s/n (PACA 26748); Derrubadas, Salto do Yucumã, 03.XII.2011, D. Grigoletto et al. 161 (SMDB); Dom Pedro de Alcântara, 20.IX.2006, F. Maraschin-Silva s/nº (ICN 145076); Giruá, Granja Sodal, 04.X.1963, sem coletor (ICN 106915); Lajeado, 26.IX.1975, sem coletor (ICN 106908); Montenegro, 19.IX.1957, Camargo 1770 s/nº 
(PACA 62396); Nova Santa Rita, 22.IX.1996, R. A. Záchia 2446 (SMDB); Novo Hamburgo, 12.VIII.1949, B. Rambo s/n (PACA 42893); Panambi, 23.IX.2011, D. Grigoletto et al. 119 (SMDB); Pareci Novo, 18.VII.1949, B. Rambo $\mathrm{s} / \mathrm{n}^{\circ}$ (PACA 42600); Picada Café, 07.X.1973, sem coletor (ICN 106916); Porto Alegre, 30.IX.1949, B. Rambo s/nº (PACA 43674); Rosário do Sul, $30^{\circ} 15,15^{\prime} \mathrm{S} / 54^{\circ} 54,48^{\prime} \mathrm{W}$, 03.IX.2011, D. Grigoletto et al. 86 (SMDB); Santa Clara do Sul, 18.XI.1940, B. Rambo s/nº (PACA 6686); Santa Maria, Camobi, UFSM, 29.IX.2010, D. Grigoletto et al. 21 (SMDB); Santiago, 22.X.2011, D. Grigoletto et al. 151 (SMDB); São Borja, XII.89, R. Záchia 62 (ICN); São Francisco de Assis, 15.X.2011, L. B. de Souza 2 (SMDB); São Leopoldo, 10.X.1946, H. Simas s/nº (PACA 35462); São Pedro do Sul, 07.X.2011, D. Grigoletto et al. 134 (SMDB); Silveira Martins, 05.X.2010, D. Grigoletto 13 (SMDB); Torres, 01.VIII.1987, K. Hagelund s/n (ICN 106862); Uruguaiana, 1957, Spies s/n (PACA 60775); Viamão, Bairro Tarumã, 26.VIII.2008, P. J. S. Silva Filho 427 (ICN).

3.19 Oxalis paludosa A. St.-Hil., Flora Brasiliae Meridionalis (quarto ed.) 1: 96, 121. 1824.

(Figuras 19 e 29-D)

Erva com até $9 \mathrm{~cm}$ de altura, decumbente, sem tricomas glandulares. Caule aéreo, entrenós aparentes. Folha palmaticomposta, insertas ao longo do caule; folíolo 0,4-0,8 x 0,5-0,9 cm, obovado, ápice cordado, incisão de 2/5 do folíolo, mais largo que comprido, ausência de glândulas punctiformes na face abaxial, concolor, pubescente; pecíolo 0,9-5,5 cm compr., glabro ou piloso; estípula $0,1-0,2 \mathrm{~cm}$ compr., largura uniforme ou alargando-se para o ápice, ápice truncado. Inflorescência 1-flora; pedicelo 1,1-2,2 cm compr., glabro ou piloso; sépala 0,4-0,6 cm compr., base não cordada, ausência de glândulas, pilosa; pétala 1-1,5 cm compr., cor amarela, glabra. Fruto não visualizado.

Hábitat: áreas abertas e ensolaradas; em campo de solo úmido.

Período de floração: outubro a janeiro.

Distribuição no Rio Grande do Sul: Campanha, Encosta Inferior do Nordeste, Litoral, Missões e Serra do Sudeste.

Material selecionado: BRASIL, RIO GRANDE DO SUL, Canguçu, terceiro Distrito de Canguçu, Coxilha do Fogo, Cabanha Sobrado Branco, 03.X.2004, F. J. M. Caporal s/n $\mathrm{n}^{\circ}$ (ICN 142633); Capivari do Sul, Fazenda dos Touros, 10.XII.2003, E. N. Garcia 863 (ICN); Lajeado, 18.XI.1940, B. Rambo s/n (PACA 4950); Quaraí, 14.I.1941, B. Rambo s/n (PACA 4132); Rio Grande, Estação Ecológica do Taim, 16.XII.1986, J. A. Jarenkow \& S. L. C. Leite 587 (PEL); Santiago, 15.X.2011, D. Grigoletto et al. 94 (SMDB); 22.X.2011, D. Grigoletto et al. 152 (SMDB).

3.20 Oxalis perdicaria (Molina) Bertero, Mercurio Chileno 16: 739. 1829.
(Figuras 20 e 29-E)

Erva com até $16 \mathrm{~cm}$ de altura, ereta, sem tricomas glandulares. Bulbo escamoso 0,4-0,6 x 0,1-0,2 cm, arredondado, entrenós muito próximos; bráctea externa com 3 nervuras, que se desintegram. Folha palmaticomposta, concentrada no ápice do caule, folíolo 0,3-1 x 0,3-1,3 cm, obovado, ápice cordado, incisão de 2/5-4/5 do folíolo, mais largo que comprido, ausência de glândulas na face abaxial, concolor, glabro ou hirsuto na face adaxial e glabro na face abaxial; pecíolo 2,7-7,2 cm compr., hirsuto; estípula não observada. Inflorescência 1-flora; pedicelo 0,5-3,5 cm compr., hirsuto; sépala 0,3-0,6 cm compr., base não cordada, ausência de glândulas, raramente presentes, pubescente; pétala 0,9-1,5 cm compr., cor amarela, glabra. Fruto 0,4-0,6 x 0,1-0,2 cm, lanceolado, glabro ou pubescente; 2-9 sementes.

Hábitat: áreas abertas e ensolaradas como campos, cultivados ou não; áreas alteradas como beira de caminhos e estradas.

Período de floração e frutificação: abril a setembro.

Distribuição no Rio Grande do Sul: Campanha, Campos de Cima da Serra, Depressão Central, Encosta do Sudeste, Litoral, Missões e Serra do Sudeste.

Material selecionado: BRASIL, RIO GRANDE DO SUL, Bagé, VI.1985, M. Sobral \& C. Grabauska 3959 (ICN); Esmeralda, sem data, L. Arzivenco 269 (ICN); Esteio, 18.V.1949, B. Rambo s/n (PACA 41624); Guaíba, Fazenda São Maximiano, 28.V.2004, V. F. Kinupp et al. 2953 (ICN); Lavras do Sul, 25.VII.1982, M. L. Porto 2880 (ICN); Pelotas, 06.X.1994, J. D. P. Bandeira s/n ${ }^{\circ}$ (PEL 11389); Porto Alegre, Parque Exposição Menino Deus, 09.VI.1975, L. Arzivenco s/n (ICN 88760); Quaraí, 29.IV.2010, I. Boldrini et al. 1650 (ICN); Restinga Seca, Santuário, 21.IV.2011, D. Grigoletto 36 (SMDB); Rio Grande, Estação Ecológica do Taim, 10.VII.1986, J. A. Jarenkow 391 (PEL); Santana do Livramento, BR 290, 03.IX.2011, D. Grigoletto et al. 91 (SMDB); Santa Maria, Camobi, UFSM, 15.IX.2011, D. Grigoletto et al. 100 (SMDB); Santa Vitória do Palmar, 27.IV.1946, J. R. S. Wallen 9225 (PEL); São Borja, 15.VI.1990, R. Záchia 235 (ICN); São Francisco de Assis, Fazenda Joaquim Paz, 18.VI.2008, E. Freitas 409 (ICN); São João do Polêsine, Vale Vêneto, 30.IX.1954, A. Sehnem s/n (PACA 104027); São Pedro do Sul, BR 287, Km 276, 12.VII.2011, D. Grigoletto et al. 44 (SMDB); São Sepé, 4.VI.2004, sem coletor (ICN 106924); Viamão, Bairro Tarumã, 16.V.2009, P. J. S. Silva Filho 430 (ICN).

\subsection{Oxalis potamophila Lourteig, Flora Ilus-} trada Catarinense 117-121, t. 18A. 1983.

\section{(Figura 21)}

Erva com até $18 \mathrm{~cm}$ de altura, ereta, sem tricomas glandulares. Bulbo escamoso 0,2 x 0,1 cm, arredondado, entrenós muito próximos; bráctea externa com 3-6 nervuras. Folha palmaticomposta, concentrada no ápice do caule; folíolo 1,1-1,8 x 0,9-2,1 cm, obovado, 
ápice cordado, incisão até $1 / 5$ do folíolo, mais largo que comprido, presença de glândulas punctiformes na face abaxial que formam manchas polimorfas, concolor, glabro; pecíolo 7,2-19,2 cm compr., glabro; estípula não observada. Inflorescência 2-4-flora, cimeira; pedicelo $1-2,7 \mathrm{~cm}$ compr., glabro; sépala $0,3-0,5 \times 0,1 \mathrm{~cm}$, base não cordada, presença de duas glândulas, glabra; pétala 1,5-1,7 cm compr., cor rosa, glabra. Fruto 0,9-1,5 x 0,2 $\mathrm{cm}$, lanceolado, glabro; 9-12 sementes.

Hábitat: áreas abertas e ensolaradas como campos; áreas alteradas como beira de caminhos e estradas.

Período de floração e frutificação: setembro a outubro.

Distribuição no Rio Grande do Sul: Depressão Central e Encosta Inferior do Nordeste.

Material selecionado: BRASIL, RIO GRANDE DO SUL, Picada Café, 07.X.1973, sem coletor (ICN 106920); Santa Maria, 18.IX.1970, sem coletor (ICN 106919).

3.22 Oxalis refracta A. St.-Hil., Flora Brasiliae Meridionalis (quarto ed.) 1: 119. 1824.

\section{(Figura 22)}

Erva com até $30 \mathrm{~cm}$ de altura, decumbente, com tricomas glandulares. Caule aéreo, ereto, entrenós aparentes. Folha palmaticomposta, insertas ao longo do caule; folíolo 0,4-1,6 x 0,5-1,6 cm, obovado, ápice cordado, incisão até $2 / 5$ do folíolo, mais largo que comprido, ausência de glândulas punctiformes na face abaxial, concolor, densamente hirsuta; pecíolo 3,7-5,4 cm compr., densamente hirsuto e pubescente; estípula 0,2-0,4 cm compr., largura uniforme, ápice agudo. Inflorescência 1-2-flora, umbela; pedicelo $0,5-1,3 \mathrm{~cm}$ compr., densamente hirsuto e pubescente; sépala 0,5-0,7 cm compr., base não cordada, ausência de glândulas, densamente hirsuta; pétala 0,9-1,9 cm compr., cor amarela, hirsuta. Fruto 0,4-0,8 x $0,4-0,5 \mathrm{~cm}$, oblongo, densamente hirsuto e pubescente; 2-3 sementes.

Hábitat: áreas abertas, alteradas e ensolaradas como beira de caminhos e estradas.

Período de floração e frutificação: agosto a outubro.

Distribuição no Rio Grande do Sul: Alto Uruguai.

Material selecionado: BRASIL, RIO GRANDE DO SUL, Giruá, Granja Sodal, 26.IX.1965, sem coletor (ICN 106927).

\subsection{Oxalis sarmentosa Zucc., Abhandlungen} der Mathematisch-Physikalischen Classe der Königlich Bayerischen Akademie der Wissenschaften 1: 244-245, t. 9. 1831.

\section{(Figura 23)}

Erva com até $39 \mathrm{~cm}$ de altura, rastejante a apoiante, com tricomas glandulares. Caule aéreo, entrenós aparentes. Folha palmaticomposta, insertas ao longo do caule; folíolo 1,3-5,7 x 0,8-3,9 cm, elíptico, ápice arredondado, inteiro a retuso, mais comprido que largo, ausência de glândulas punctiformes na face abaxial, discolor, hirsuto; pecíolo 2,9-33,8 cm compr., hirsuto; estípula 0,4 cm compr., estreitando-se para o ápice, ápice cuneado. Inflorescência 2-8-flora, cimeira; pedicelo 1-1,5 cm compr., hirsuto; sépala 0,3-0,4 cm compr., base não cordada, ausência de glândulas, hirsuta; pétala 1-1,1 cm compr., cor amarela, glabra. Fruto 0,4 x 0,6 cm, oblado, hirsuto; 1 semente.

Hábitat: áreas fechadas e sombreadas, como interior de mato; áreas alteradas como beira de caminhos e estradas, e em beira de barranco.

Período de floração e frutificação: fevereiro a agosto.

Distribuição no Rio Grande do Sul: Campos de Cima da Serra, Encosta do Sudeste e Encosta Superior do Nordeste.

Material selecionado: BRASIL, RIO GRANDE DO

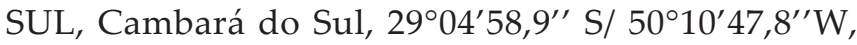
15.II.2012, D. Grigoletto et al. 189 (SMDB); Caxias do Sul, 15.VII.1954, B. Rambo s/nº (PACA 55868); Pelotas, 22.V.1959, J. C. Sacco 1257 (PEL); São José dos Ausentes, $29^{\circ} 24^{\prime} 25,2^{\prime \prime} \mathrm{S} / 50^{\circ} 27^{\prime} 25,4^{\prime \prime} \mathrm{W}, 16 . I I .2012$, D. Grigoletto et al. 190 (SMDB).

\subsection{Oxalis sellowiana var. alba Múlgura, Darwiniana 18(1-2): 51. 1973.}

(Figuras 24 e 29-F)

Erva com até $13 \mathrm{~cm}$ de altura, ereta, sem tricomas glandulares. Bulbo escamoso 0,4-0,6 x 0,2-0,4 cm, arredondado, entrenós muito próximos; bráctea externa com 5 nervuras, que se desintegram. Folha palmaticomposta, concentrada no ápice do caule, folíolo 0,5-1 x 0,5-0,9 $\mathrm{cm}$, obovado, ápice cordado, incisão até $2 / 5$ do folíolo, mais comprido que largo ou igual tamanho, presença de glândulas punctiformes na face abaxial que não formam manchas polimorfas, concolor, glabro na face adaxial e densamente seríceo na face abaxial; pecíolo $6,1-13 \mathrm{~cm}$ compr., densamente seríceo; estípula não observada. Inflorescência 1-flora; pedicelo 0,5-1,1 cm compr., densamente seríceo; sépala 0,3-0,6 cm compr., base não cordada, presença de duas glândulas, densamente serícea; pétala 1,2-2,6 cm compr., cor branca e borda purpúrea, serícea. Fruto 0,4-0,6 x 0,2-0,4 cm, oblongo, seríceo; 6 sementes.

Hábitat: áreas abertas e ensolaradas como campos, cultivados ou não; áreas alteradas como beira de caminhos e estradas.

Período de floração e frutificação: abril a agosto.

Distribuição no Rio Grande do Sul: Campanha, Depressão Central, Encosta do Sudeste e Serra do Sudeste.

Material selecionado: BRASIL, RIO GRANDE DO SUL, Alegrete, 02.V.1986, R. Wasum s/nº (PACA 1489); Bagé, VI.1995, M. Sobral \& C. Grabauska 3960 (ICN); Cachoeira do Sul, 08.VII.1974, Valls 3304 \& Matzenbacher 90 (ICN); Caçapava do Sul, 30.V.1976, M. L Porto et al. 2201 (ICN); Canguçu, BR 392, Km 140, Restaurante Fitazul, 29.VIII.2011, D. Grigoletto et al. 81 (SMDB); Lavras do Sul, 12.V.1970, J. C. Lindeman s/nº (ICN 6257); Pelotas, 19.V.1959, J. C. Sacco 1184 (PEL); Quaraí, 29.IV.2010, I. 
Boldrini et al. 1646 (ICN).

3.25 Oxalis subvillosa Norlind, Arkiv för Botanik utgivet av K. Svenska Vetenskapsakademien 14(6): 13-14, t. 3, f. 2. 1915.

\section{(Figuras 25 e 29-G)}

Erva com até $60 \mathrm{~cm}$ de altura, decumbente, sem tricomas glandulares. Caule aéreo, ereto, entrenós aparentes. Folha palmaticomposta, insertas ao longo do caule; folíolo 0,6-1 x 0,6-1 cm, obovado, ápice cordado, incisão até $2 / 5$ do folíolo, mais largo que comprido, ausência de glândulas punctiformes na face abaxial, concolor, adpresso pubescente; pecíolo 0,8-2,5 cm compr., adpresso pubescente; estípula 0,1-0,2 cm compr., estreitando-se para o ápice, ápice agudo, caducas. Inflorescência 1-3-flora, umbela; pedicelo 0,7-1,1 cm compr., adpresso pubescente; sépala 0,3-0,5 cm compr., base cordada, ausência de glândulas, adpresso pubescente; pétala $1 \mathrm{~cm}$ compr., cor amarela, glabra. Fruto não observado.

Hábitat: áreas úmidas e sombreadas. Encontrada em barranco na beira do rio no interior do mato.

Período de floração: novembro.

Distribuição no Rio Grande do Sul: Depressão Central.

Material selecionado: BRASIL, RIO GRANDE DO SUL, São Martinho da Serra, 04.XI.2012, T. Canto-Dorow et al.1242 (SMDB).

\subsection{Oxalis tenerrima R. Knuth, Repertorium} Specierum Novarum Regni Vegetabilis 23: 277. 1927.

\section{(Figuras 26 e 29-H)}

Erva com até $9 \mathrm{~cm}$ de altura, estolonífera, sem tricomas glandulares. Caule aéreo, rastejante, entrenós aparentes. Folha palmaticomposta, insertas ao longo do caule; folíolo 0,2-0,7 x 0,2-1 cm, obovado, ápice cordado, incisão de $3 / 5$ do folíolo, mais largo que comprido, ausência de glândulas punctiformes na face abaxial, concolor, glabro ou adpressa pubescente; pecíolo $0,7-7,9 \mathrm{~cm}$ compr., glabro ou adpresso pubescente; estípula 0,1-0,2 cm compr., largura uniforme, ápice truncado-cuneada. Inflorescência 1-flora; pedicelo 0,3-0,8 cm compr., adpresso pubescente; sépala 0,2-0,4 cm compr., base não cordada, ausência de glândulas, glabra ou adpressa pubescente; pétala 0,4-0,9 cm compr., cor amarela, glabra. Fruto 0,3-0,6 x 0,2-0,3 $\mathrm{cm}$, oblongo a ovado, adpresso pubescente; $3-5$ sementes.

Hábitat: áreas abertas e ensolaradas como campos; áreas alteradas como beira de caminhos e estradas.

Período de floração e frutificação: julho a fevereiro.

Distribuição no Rio Grande do Sul: Alto Uruguai, Campos de Cima da Serra, Depressão Central, Encosta Inferior do Nordeste, Litoral e Planalto Médio.

Material selecionado: BRASIL, RIO GRANDE DO SUL, Bom Jesus, 21.I.1975, sem coletor (ICN 106934); Canela, Cascata do Caracol, 08.I.2012, D. Grigoletto 170 (SMDB 170); Caxias do Sul, 26.XI.2010, I. Boldrini 1655
(ICN); Esmeralda, 30.IX.1984, L. R. M. Baptista et al. s/ $\mathrm{n}^{\circ}$ (ICN 62674); Gramado, 07.I.2012, D. Grigoletto 167 (SMDB); Itati, $29^{\circ} 27^{\prime} 0,7^{\prime \prime}$ S/ 50 $0,7^{\prime} 43,2^{\prime \prime} \mathrm{W}, 15 . \mathrm{II} .2012$, D. Grigoletto et al. 183 (SMDB); Palmeira das Missões, 03.XII.2011, D. Grigoletto et al. 163 (SMDB); Panambi, 23.IX.2011, D. Grigoletto et al. 118 (SMDB); São Francisco de Paula, 26.XI.2010, I. Boldrini 1660 (ICN); Viamão, Bairro Tarumã, 30.VII.2009, P. J. S. Silva Filho 422 (ICN).

3.27 Oxalis triangularis A. St.-Hil., Flora Brasiliae Meridionalis (quarto ed.) 1: 102. 1825.

\section{(Figuras 27 e 29-I)}

Erva com até $34 \mathrm{~cm}$ de altura, ereta, sem tricomas glandulares. Bulbo escamoso 1,6-3,5 x 0,4-1,5 cm, alongado, entrenós afastados; bráctea externa com 3 nervuras. Folha palmaticomposta, concentrada no ápice do caule; folíolo 1-4,6 x 1,8-7,8 cm, obovado, ápice truncado, incisão até $1 / 5$ do folíolo, mais largo que comprido, ausência ou presença de glândulas punctiformes na incisão que não formam manchas polimorfas, concolor, glabro; pecíolo 4,2-32,1 cm compr., glabro ou piloso; estípula não observada. Inflorescência 3-4-flora, umbela; pedicelo 2,0-3,7 cm compr., glabro; sépala 0,3-0,7 cm compr., base não cordada, presença de duas glândulas, glabra; pétala 1,3$2,4 \mathrm{~cm}$ compr., cor branca, glabra. Fruto $0,8-1,8 \times 0,2-0,4$ $\mathrm{cm}$, ovado, glabro; 5-6 sementes.

Hábitat: áreas fechadas e sombreadas como beira de mato.

Período de floração e frutificação: agosto a março.

Distribuição no Rio Grande do Sul: Alto Uruguai, Depressão Central, Encosta do Sudeste, Encosta Inferior do Nordeste, Litoral, Planalto Médio e Missões.

Material selecionado: BRASIL, RIO GRANDE DO SUL, Augusto Pestana, 05. IX.1953, R. Reitz 557 (PACA); Esteio, 24.XI.1948, B. Rambo s/nº (PACA 38322); Giruá, 25.X.1966, sem coletor (ICN 106935); Guaíba, 13.III.1984, N. I. Matzenbacher s/n ${ }^{\circ}$ (ICN 59575); Itati, $29^{\circ} 27^{\prime} 0,79^{\prime \prime} \mathrm{S} /$ $50^{\circ} 0,7^{\prime} 43,2^{\prime \prime} \mathrm{W}, 15 . \mathrm{II} .2012$, D. Grigoletto et al. 182 (SMDB); Itaqui, $29^{\circ} 24^{\prime} 27,8^{\prime \prime} \mathrm{S} / 50^{\circ} 10^{\prime} 31,7^{\prime \prime} \mathrm{W}$, 15.II.2012, D. Grigoletto et al. 186 (SMDB); Pareci Novo, 03.X.1945, A. Sehnem s/n ${ }^{\circ}$ (PACA 8727); Passo Fundo, 30.X.1971, J. C. Lindeman et al. s/n $\mathrm{n}^{\circ}$ (ICN 8777); Pelotas, 10.IX.1976, L. Arzivenco s/n (ICN 50283); Picada Café, 29 $29^{\prime} 34^{\prime \prime} \mathrm{S} /$ 5109'10,6”' W, 14.II.2012, D. Grigoletto et al. 176 (SMDB); Porto Alegre, 1950, K. Emrich s/n (PACA 47301); Santa Maria, Camobi, Faixa Nova, 12.III.2012, D. Grigoletto et al. 207 (SMDB); São Francisco de Assis, 15.X.2011, L. B. de Souza 1 (SMDB); São Leopoldo, 04.XII.1934, B. Rambo s/n (PACA 1277); Viamão, Bairro Tarumã, 15.VIII.2009, P. J. S. Silva Filho 425 (ICN). 

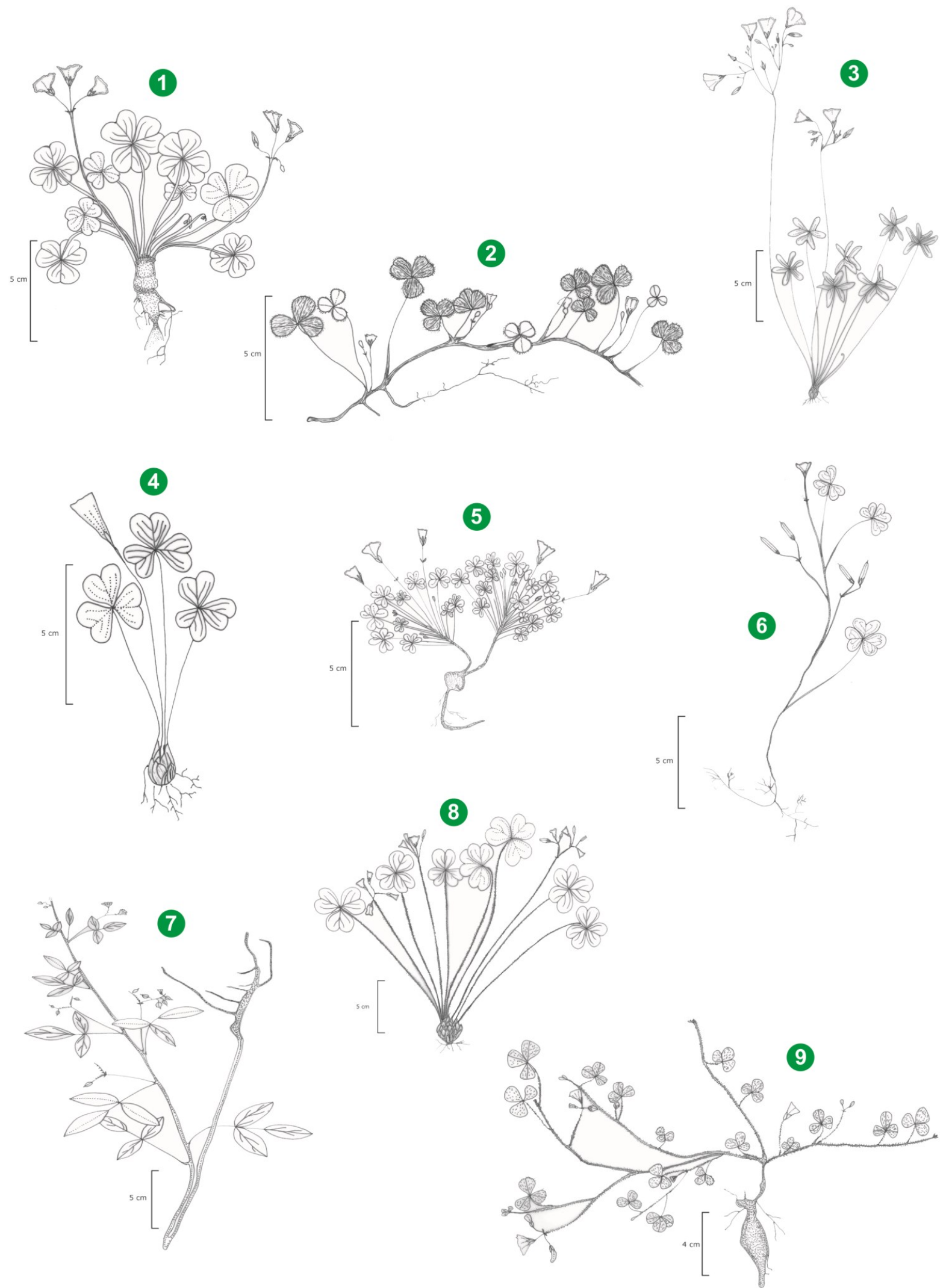

Figura 1 - Oxalis articulata (Canto-Dorow, T. et al., 1240-SMDB); Figura 2 - Oxalis bifrons (Canto-Dorow, T. et al., 1236-SMDB); Figura 3 - Oxalis bipartita (Grigoletto, D. et al., 89-SMDB); Figura 4 - Oxalis brasiliensis (Grigoletto, D. et al., 106-SMDB); Figura 5- Oxalis conorrhiza (Grigoletto, D. et al., 164-SMDB); Figura 6 - Oxalis corniculata (Grigoletto, D. et al., 125-SMDB); Figura 7 - Oxalis cytisoides (Grigoletto, D. et al., 162-SMDB); Figura 8 - Oxalis debilis (Grigoletto, D. et al., 133-SMDB); Figura 9- Oxalis eriocarpa (Grigoletto, D. et al., 123-SMDB). 
10

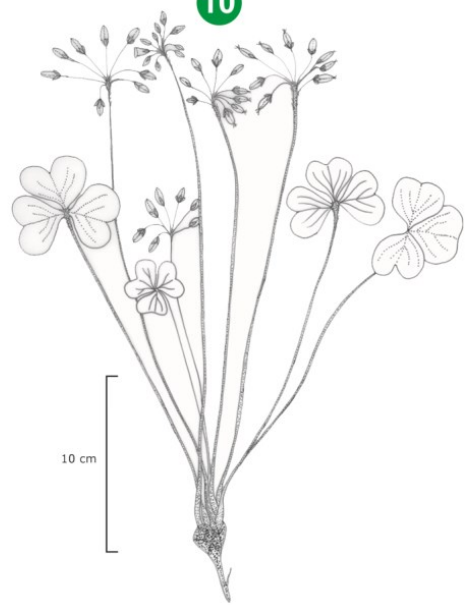

13

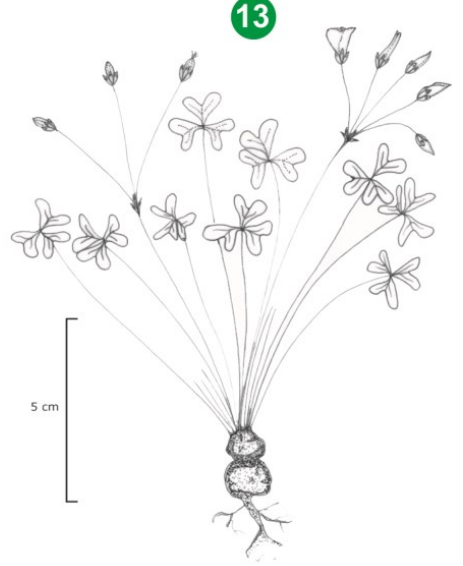

16

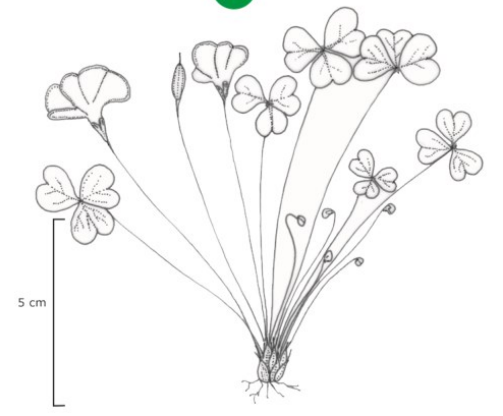

(11)

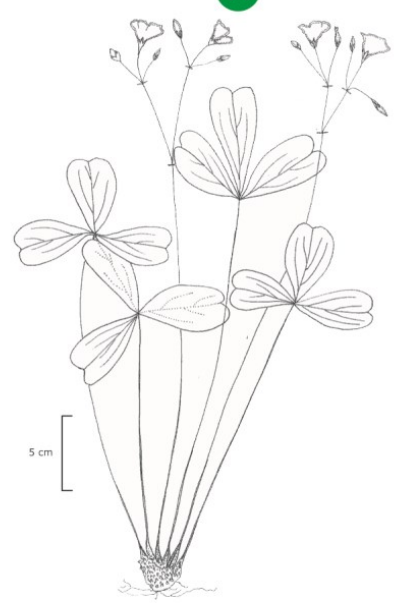

14

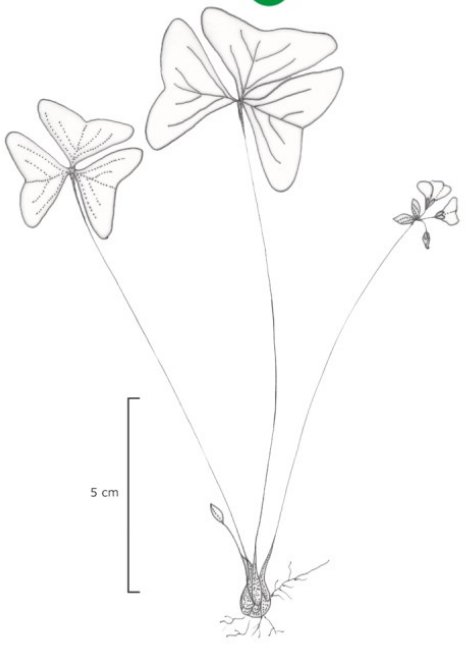

17

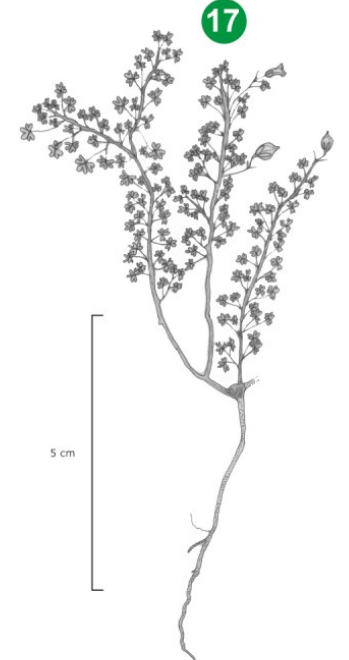

12

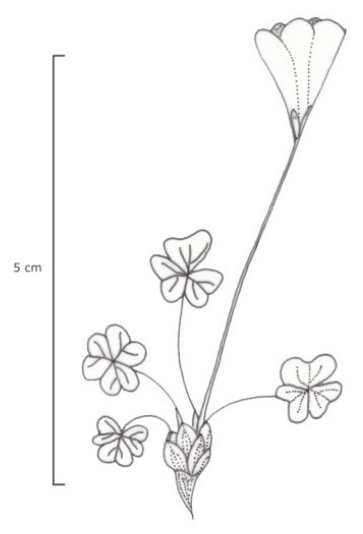

(15)

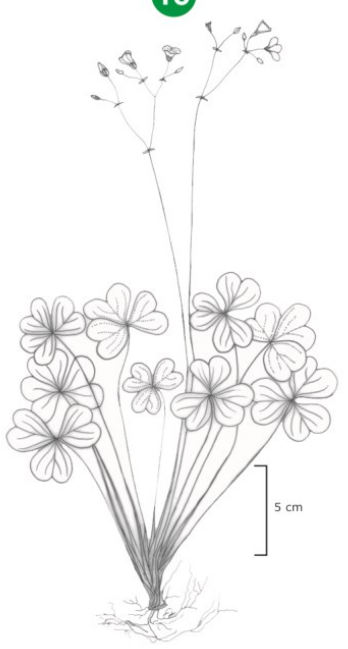

18

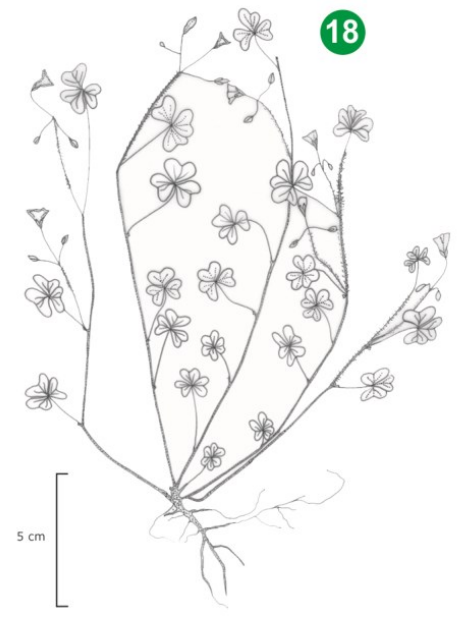

Figura 10 - Oxalis floribunda (Grigoletto, D. et al., 102-SMDB); Figura 11 - Oxalis geralensis (Ritter, M. R., et al., 570-SMDB); Figura 12 - Oxalis hispidula (Grigoletto, D. et al., 139-SMDB); Figura 13 - Oxalis lasiopetala (Grigoletto, D. et al., 105-SMDB); Figura 14 - Oxalis latifolia (Grigoletto, D. et al., 208-SMDB); Figura 15 - Oxalis linarantha (Grigoletto, D. et al., 85-SMDB); Figura 16 - Oxalis lindneri (Grigoletto, D. et al., 43-SMDB); Figura 17 - Oxalis myriophylla (Irgang, B. et al., s. n. - ICN92763); Figura 18-Oxalis niederleinii (Grigoletto, D. et al., 69-SMDB). 
19

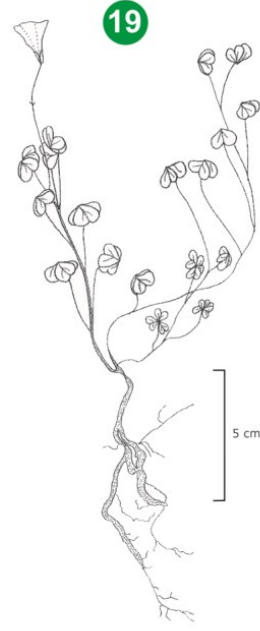

20
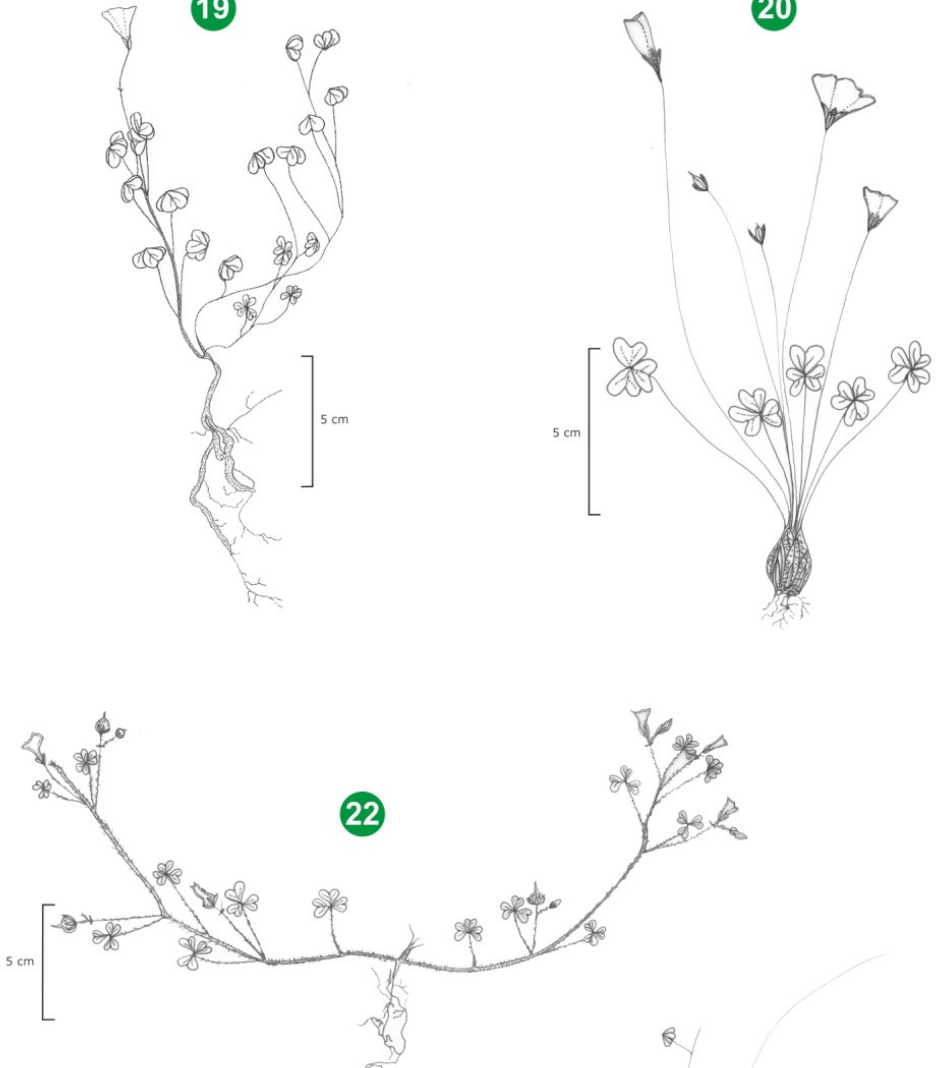

24

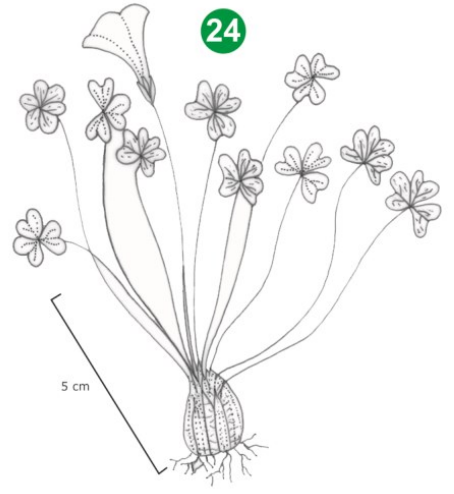

26

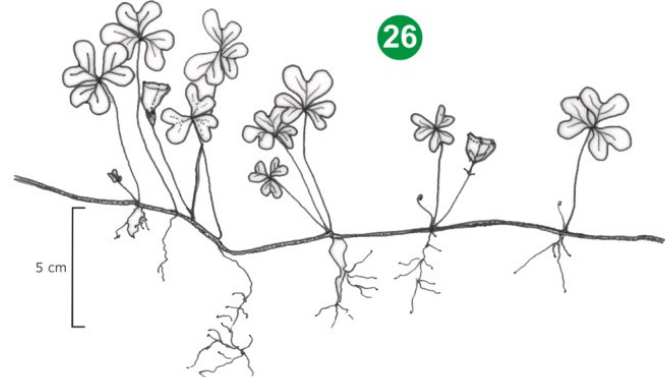

21
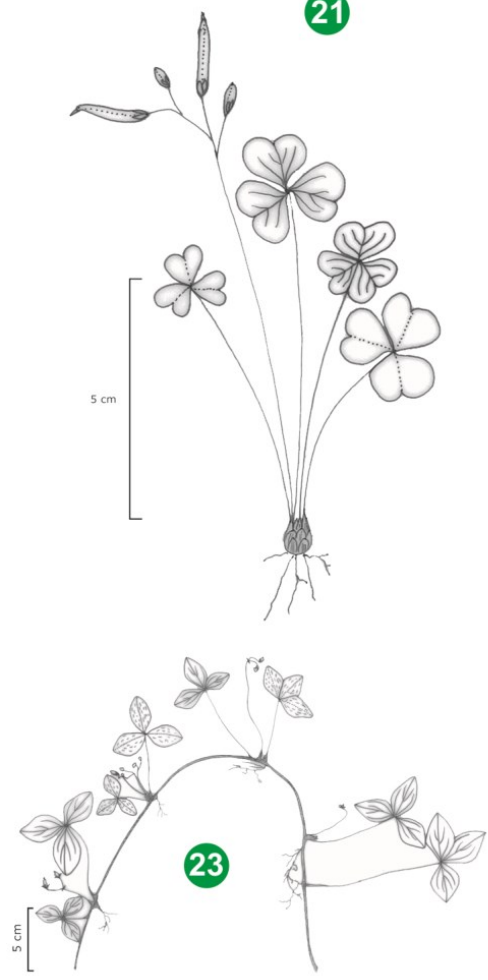

25

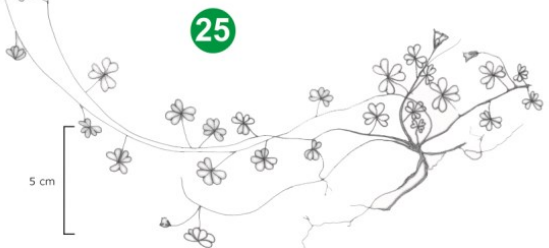

Figura 19 - Oxalis paludosa (Grigoletto, D. et al.,94-SMDB); Figura 20 - Oxalis perdicaria (Grigoletto, D. et al., 44-SMDB); Figura 21 - Oxalis potamophila (s. col. - ICN106920); Figura 22 - Oxalis refracta (s. col. - ICN106846); Figura 23 - Oxalis sarmentosa (Knupp et al., s. n. - ICN2449); Figura 24 - Oxalis sellowiana var. alba (Grigoletto, D. et al., 232-SMDB); Figura 25 - Oxalis subvillosa (Canto-Dorow, T. et al., 1242-SMDB); Figura 26 - Oxalis tenerrima (Grigoletto, D. et al., 167-SMDB); Figura 27 - Oxalis triangularis (Grigoletto, D. et al., 207-SMDB). 

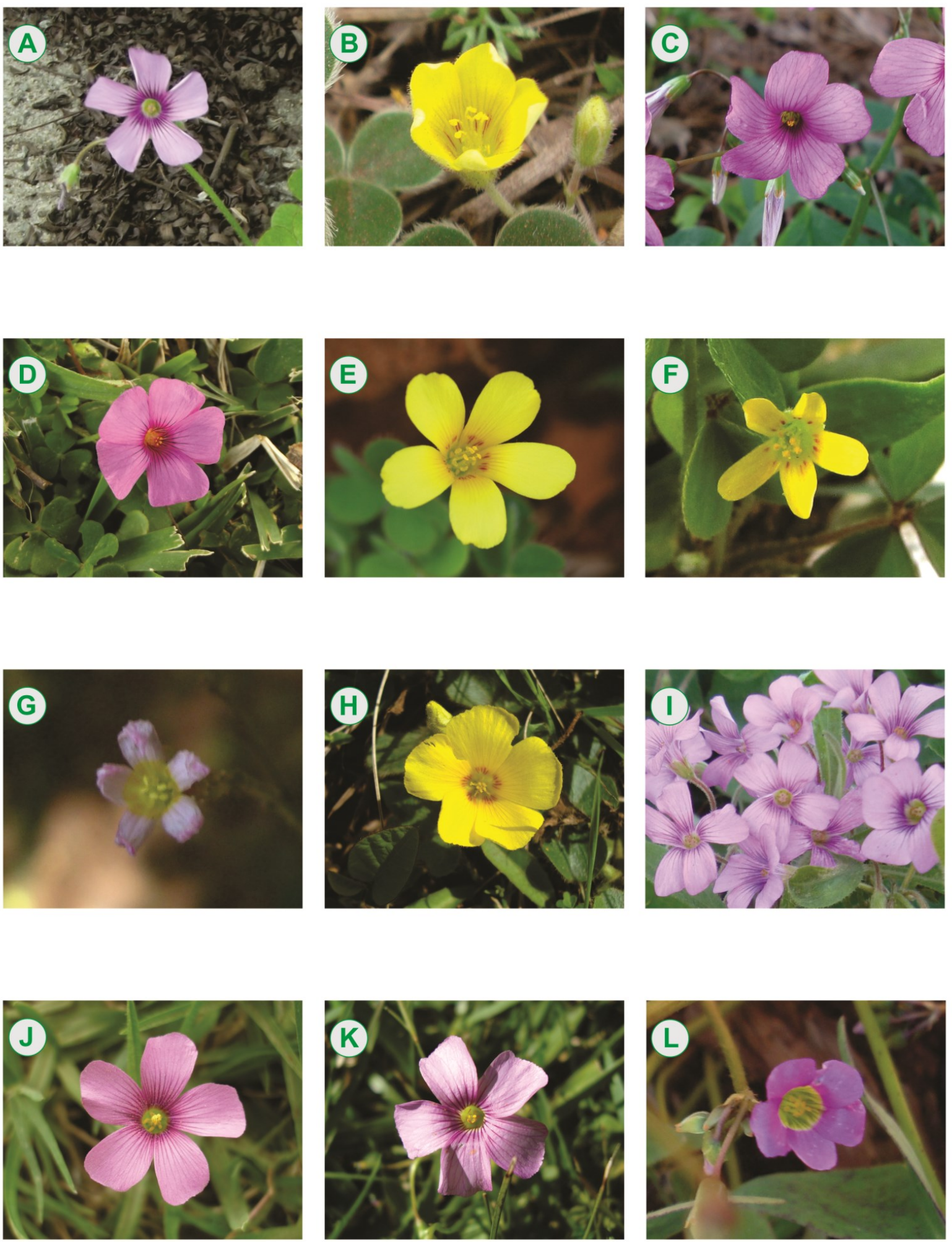

Figura 28 -Aspecto geral da flor. A - Oxalis articulata (Canto-Dorow, T. et al., 1240-SMDB); B - Oxalis bifrons (Canto-Dorow, T. et al., 1236-SMDB); C - Oxalis bipartita (Grigoletto, D et al., 89-SMDB); D - Oxalis brasiliensis (Grigoletto, D et al., 106-SMDB); E - Oxalis conorrhiza (Grigoletto, D et al., 164-SMDB); F-Oxalis corniculata (Grigoletto, D. et al., 125-SMDB); G - Oxalis cytisoides (Grigoletto, D. et al., 162-SMDB); H - Oxalis eriocarpa (Grigoletto, D. et al., 123SMDB); I - Oxalis floribunda (Grigoletto, D. et al., 102-SMDB); J - Oxalis hispidula (Grigoletto, D. et al., 139-SMDB); K - Oxalis lasiopetala (Grigoletto, D. et al., 105-SMDB); L- Oxalis latifolia (Grigoletto, D. et al., 208-SMDB). 

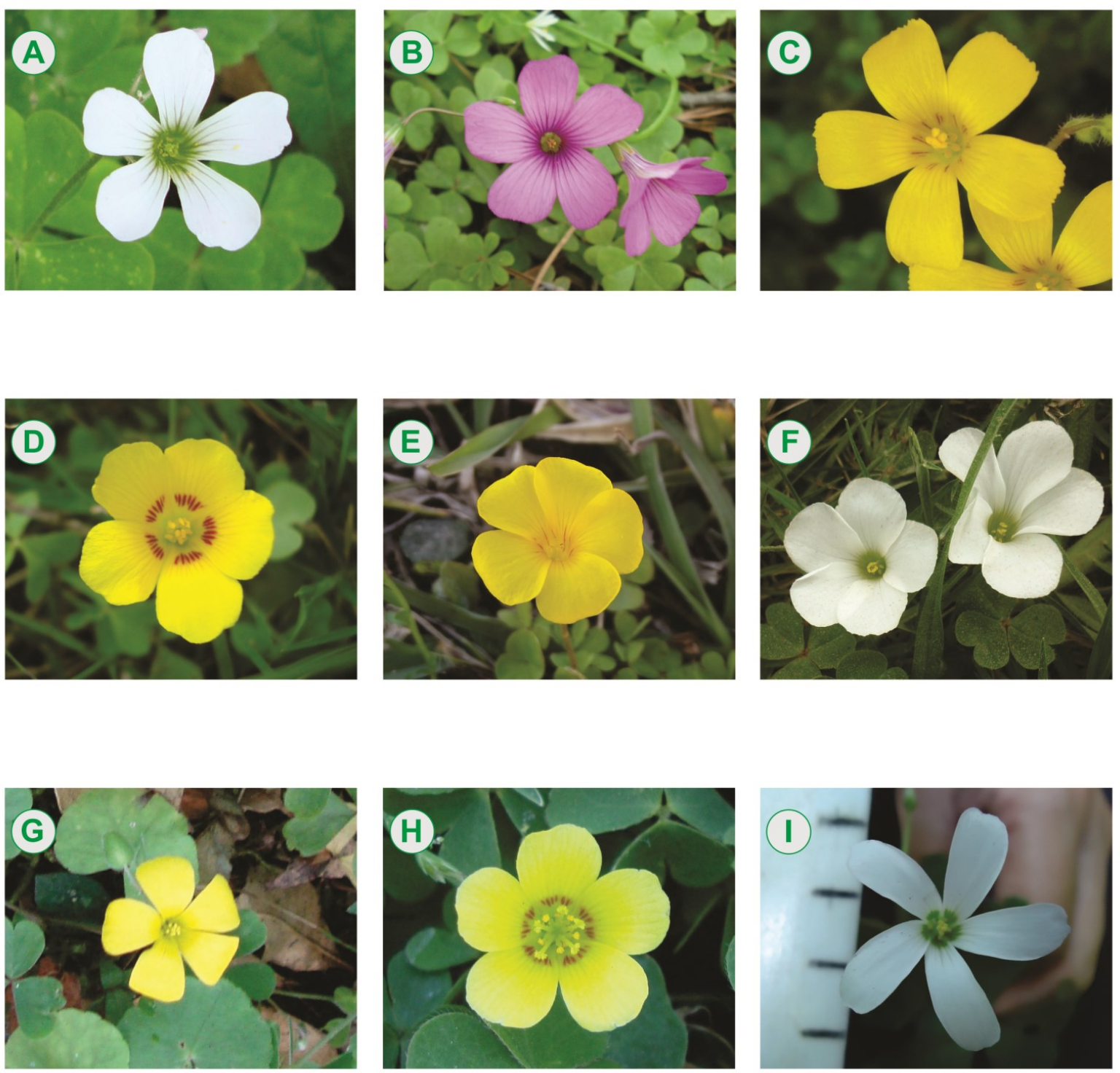

Figura 29 - Aspecto geral da flor. A - Oxalis linarantha (Grigoletto, D. et al., 85-SMDB); B - Oxalis lindneri (Grigoletto, D. et al., 43-SMDB); C - Oxalis niederleinii (Grigoletto, D. et al., 69-SMDB); D - Oxalis paludosa (Grigoletto, D. et al., 94-SMDB); E - Oxalis perdicaria (Grigoletto, D. et al., 44-SMDB); F- Oxalis sellowiana var. alba (Grigoletto, D. et al., 232-SMDB); G - Oxalis subvillosa (Canto-Dorow, T. et al., 1242-SMDB); H - Oxalis tenerrima (Grigoletto, D. et al., 167-SMDB); I- Oxalis triangularis (Grigoletto, D. et al., 207-SMDB).

\section{Conclusão}

O gênero Oxalis está representado no Rio Grande do Sul por 27 espécies: Oxalis articulata Savigny, Oxalis bifrons Progel, Oxalis bipartita A. St.-Hil., Oxalis brasiliensis G. Lodd., Oxalis conorrhiza Jacq., Oxalis corniculata L., Oxalis cytisoides C. Mart. \& Zucc., Oxalis debilis Kunth, Oxalis eriocarpa DC., Oxalis floribunda Lehm., Oxalis geralensis R. Knuth, Oxalis hispidula Zucc., Oxalis lasiopetala Zucc., Oxalis latifolia Kunth, Oxalis linarantha Lourteig, Oxalis lindneri R. Knuth, Oxalis myriophylla A. St.-Hil., Oxalis niederleinii R. Knuth, Oxalis paludosa A. St.-Hil., Oxalis perdicaria (Molina) Bertero, Oxalis potamophila Lourteig,
Oxalis refracta A. St.-Hil., Oxalis sarmentosa Zucc., Oxalis sellowiana var. alba Múlgura, Oxalis subvillosa Norlind, Oxalis tenerrima R. Knuth e Oxalis triangularis A. St.-Hil.

A espécie Oxalis subvillosa é nova ocorrência no Rio Grande do Sul e, Oxalis lindneri, um novo registro no Brasil.

As espécies Oxalis geralensis, Oxalis myriophylla, Oxalis potamophila e Oxalis refracta A. St.-Hil. não foram coletadas neste trabalho.

Constatou-se a presença de espécies do gênero Oxalis em todas as regiões fisiográficas do Rio Grande do Sul, sendo a Depressão Central, a mais representativa (20 espécies), seguida, do Litoral e Missões, com 15 e 14 
espécies, respectivamente.

Oxalis bipartita foi a única comum em todas as regiões fisiográficas. Oxalis linarantha só não foi encontrada na Campanha e Oxalis niederleinii, nos Campos de Cima da Serra e na Encosta Superior do Nordeste.

Oxalis cytisoides e Oxalis refracta foram encontradas exclusivamente na região do Alto Uruguai, assim como, Oxalis lindneri e Oxalis subvillosa na Depressão Central e, Oxalis myriophylla, na Campanha.

\section{Referências}

Abreu, M.C. de. 2007. Sistemática do gênero Oxalis L. (Oxalidaceae R. Br.) no estado de Pernambuco, Brasil. 65 f. Dissertação (Mestrado em Botânica), Universidade Federal Rural de Pernambuco, Pernambuco.

Abreu, M.C. de \& Fiaschi, P. 2009. Oxalidaceae. Plantas da Floresta Atlântica. Disponível em: $<$ http://cncflora.jbrj.gov.br/plataforma2/arquivos/ biblio/4f6cb87e40444_4f560f1092fdf_4f560eaecba1f_ plantas_floresta_atlantica.pdf $>$. Acesso em 22.01.2013.

Abreu, M.C. de \& Fiaschi, P. 2013. Oxalidaceae. Lista de Espécies da Flora do Brasil. Disponível em: $<$ http://floradobrasil.jbrj.gov.br/2010/FB000181>. Acesso em 22.01.2013.

Appezzato-da-Glória, B. 2003. Morfologia de sistemas subterrâneos: histórico e evolução do conhecimento no Brasil. Ribeirão Preto: A.S. Pinto. 80 p.

Corrêa, M.P. 1926. Diccionário das plantas úteis do Brasil e das exóticas cultivadas. Rio de Janeiro: Imprensa Nacional. (v. VI).

Corrêa, M.P. 1984. Diccionário das plantas úteis do Brasil e das exóticas cultivadas. Rio de Janeiro: Imprensa Nacional. (v. II).

Fiaschi, P. \& Conceição, A.A. 2005. Oxalidaceae. In: Flora fanerogâmica do estado de São Paulo (M.G. Wanderley, G.J. Shepherd, T.S. Melhem \& A.M. Giulietti, Eds.). São Paulo: RiMa. 4 v. p. 301-315.

Fortes, A.B. 1959. Geografia física do Rio Grande do Sul. Porto Alegre: ed. Globo. 393 p.

Gonçalves E.G. \& Lorenzi H. 2011. Morfologia vegetal: organografia e dicionário ilustrado de morfologia das plantas vasculares. São Paulo: Instituto Plantarum. 2. ed. 512 p.
Kissmann, K.G. \& Groth, D. 2000. Oxalidaceae R. Br. In: Plantas infestantes e nocivas. São Paulo: BASF. Tomo III. 2. ed. p. 248-260.

Lourteig, A. 1983. Oxalidáceas. Flora Ilustrada Catarinense: I Parte Fascículo. Itajaí: Herbário "Barbosa Rodrigues". 174 p.

Radford, A.E., Dickison, W.C., Massey, J.R. \& Bell, C.R. 1974. Vascular plant systematics. New York: Harper \& Row Publishers. 891 p.

Stevens, P.F. 2001. Angyosperm phylogeny website. Disponível em: <http://www.mobot.org/MOBOT/ research/APweb//>. Acesso em 22.01.2011.

Souza, V.C. \& Lorenzi, H. 2008. Botânica sistemática: guia ilustrado para identificação das famílias de fanerógamas nativas e exóticas no Brasil, baseado em APG II. São Paulo: Instituto Plantarum. 2. ed. $703 \mathrm{p}$.

Souza, F.O. \& Bianchini, R.S. 2000. Flora fanerogâmica da Reserva do Parque Estadual das Fontes do Ipiranga: 119 - Oxalidaceae. Hoehnea. São Paulo, v 27(2): 117-120.

Thiers, B. [continuously updated]. 2012. Index Herbariorum: A global directory of public herbaria and associated staff. Disponível em: $<$ http:// sweetgum.nybg.org/ih/>. Acesso em 08.06.2013. 